\title{
RESTAURACIÓN DE "SAN FRANCISCO EL GRANDE". MADRID. ESPAÑA
}

\author{
(RESTORATION OF THE "SAN FRANCISCO EL GRANDE" CHURCH. MADRID. SPAIN)
}

Ignacio, Javier y Luz Feduchi Benlliure, Arquitectos

Luis Fernández Aldaco, Aparejador

Fecha de recepción: $8-1 \mathrm{X}-88$

\section{RESUMEN}

El contenido del presente articulo se refiere a las obras de restauración de uno de los monumentos más importantes de nuestra capital.

Después de explicar el proceso burocrático que conduce al encargo del proyecto, se da una reseña histórica del famoso templo, de cuya lectura se desprenden los problemas tecnológicos existentes y la responsabilidad de acometer la restauración teniendo en cuenta las pinturas que existían en el interior. Detalla el articulo la elección de materiales y procedimientos empleados, todo ello ilustrado con interesante documentación gráfica.

\section{SUMMARY}

This article considers the restoration work being carried out on one of the most important monuments of the capital.

After outlining the burocratic process leading up to the awarding of the project, a brief historical survay of the temple is given. The technological problems entailed, as well as the responsibility of carrying out a restoration keeping in mind the church's interior paintings, are made clear in this outline. The article goes on to specify the materials selected and the procedures used, and is illustrated with interesting photos.

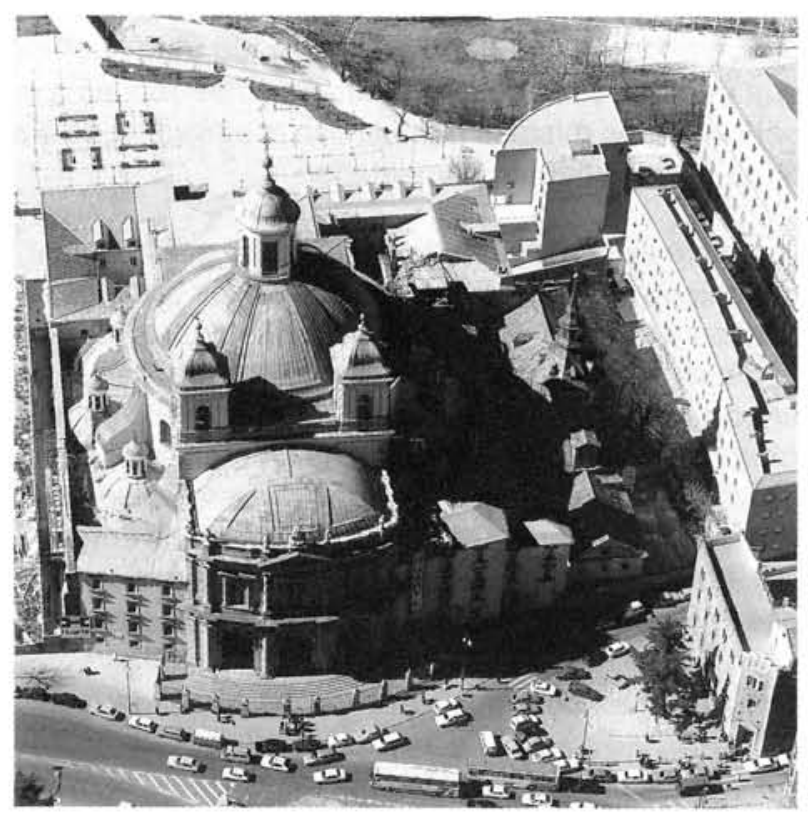

Para exponer nuestro trabajo tenemos que remitirnos al encargo que en febrero de 1973 hace la Obra Pia de Jerusalén, propietaria del templo, al arquitecto del Ministerio de Asuntos Exteriores, Luis Feduchi, para que con toda urgencia elabore un "Proyecto de Presupuesto" que proporcione una cifra de partida para la restauración del edificio, textualmente "a fin de evitar el cierre de dicho templo, que tanto utiliza el Estado".

A tal efecto se constituyó un equipo junto al estudio de arquitectura, con aparejadores y profesionales especializados (ingenieros de estructura, químicos, restauradores de pinturas, de revocos, plomeros, etcétera).

Las características singulares de la obra indicaban un tipo de ejecución de los trabajos como era el que habitualmente hacia la Comisaría de Bellas Artes; es decir, una contratación directa a los especialistas más cualificados en cada fase.

NOTA: El presente articulo es la conferencia que se dictó con motivo de las "Jornadas sobre criterios de intervención en el Patrimonio Arquitectónico", organizadas por el Ministerio de Cultura. 


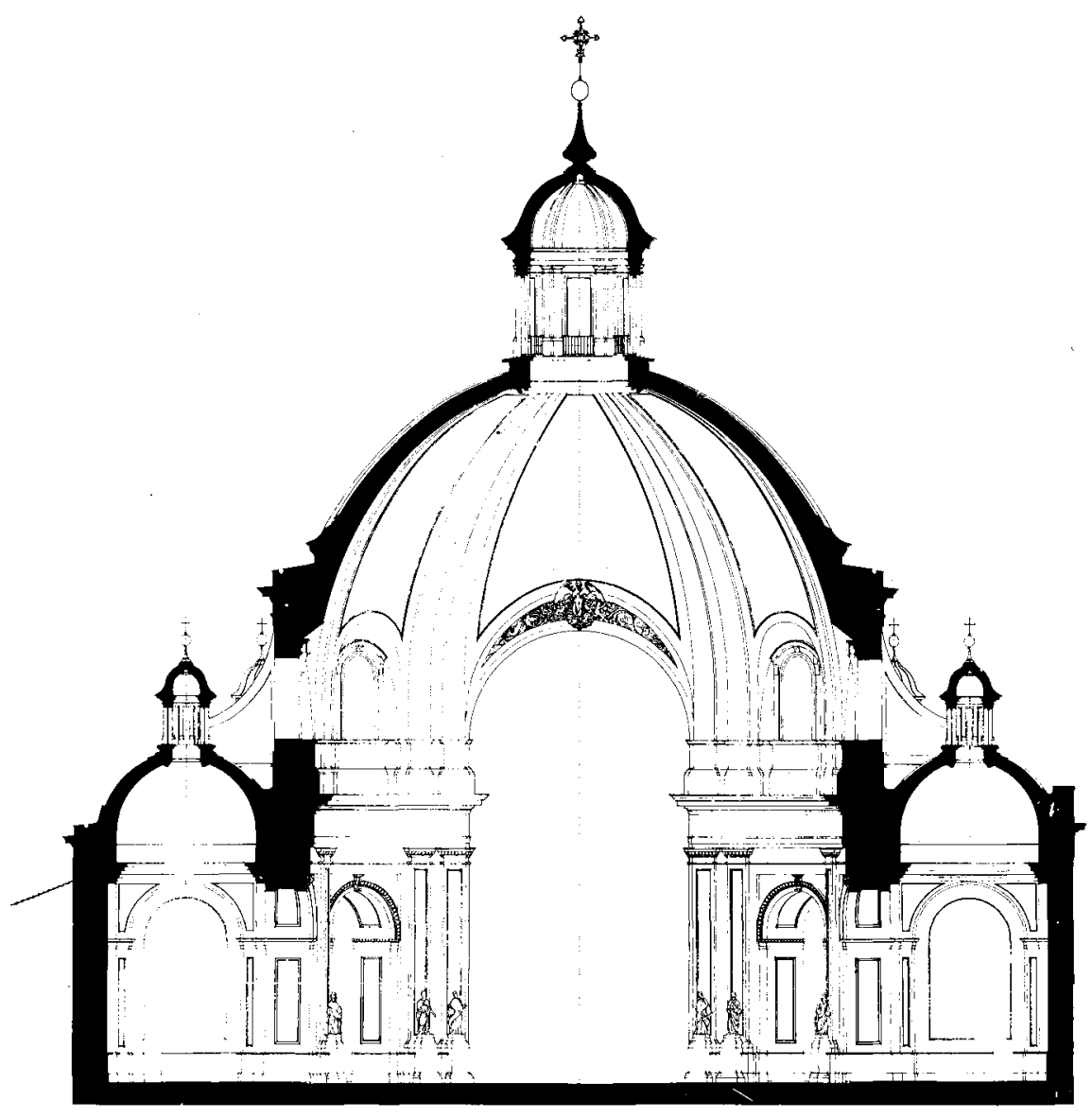

Sección transversal.

Por razones ajenas a este planteamiento, el Ministerio de Asuntos Exteriores quedó excluido del desarrollo del presupuesto y de la redacción del proyecto definitivo; y se encargó el Patrimonio del Estado de llevar a cabo la restauración, sin confeccionar proyecto y tomando como documento básico el citado "Proyecto de Presupuesto" elaborado por el equipo de Luis Feduchi.

En julio de 1984, la Dirección General de Bellas Artes del Ministerio de Cultura, basándose en el conocimiento que teniamos del estado del edificio antes de la última reforma, y ante el aparente fracaso de ésta, nos encarga la redacción del Proyecto de Restauración de San Francisco el Grande.

La visita al edificio, y la toma de referencias comparativas con los datos que teniamos del año 1973, evidenciaba que el tipo de restauración realizada había sido inútil.

Ante la carencia de un proyecto y de una documentación gráfica reciente, nos tenemos que apoyar en los planos que contenia el "Proyecto de Presupuesto", los cuales procedian del levantamiento que se hizo en los años 40 por la Dirección General de Arquitectura, corregidos con los datos tomados en su día para el "presupuesto".

(c) Consejo Superior de Investigaciones Científicas

Licencia Creative Commons 3.0 España (by-nc)
Solamente disponiamos de un pequeño reportaje fotográfico que hicimos en 1973, el cual nos permitía hacer una comparación del estado del edificio en ese año y en el de nuestro encargo (1984). Fácilmente se podia observar que el resultado no había sido todo lo eficaz que debiera, y los desperfectos de antes volvian a repetirse en los mismos puntos, con el agravante de que en el interior habian aumentado.

Tampoco existía un estudio histórico ni gráfico (planos o dibujos), que nos permitiera conocer los cambios realizados a lo largo de las obras. Este estudio histórico lo hicimos ciñéndonos a una cronologia de los hechos importantes en relación con la construcción, restauración o costos de los trabajos que afectaban a nuestro proyecto, $\sin$ incluir los aspectos ornamentales del interior por resultarnos ajenos. Consideramos entonces las fechas de acontecimientos históricos, las variaciones de uso, cambio de propietario, arquitectos, etcétera.

\section{Comenzamos con una breve reseña histórica:}

En 1760 se procede a la demolición del viejo convento y se encarga a Ventura Rodríguez el proyecto. Rechazado éste por la Orden franciscana, lo comienza a hacer Fray Antonio Cabezas que, a pesar de los informes contradictorios de la Academia, lo lleva a cabo hasta 


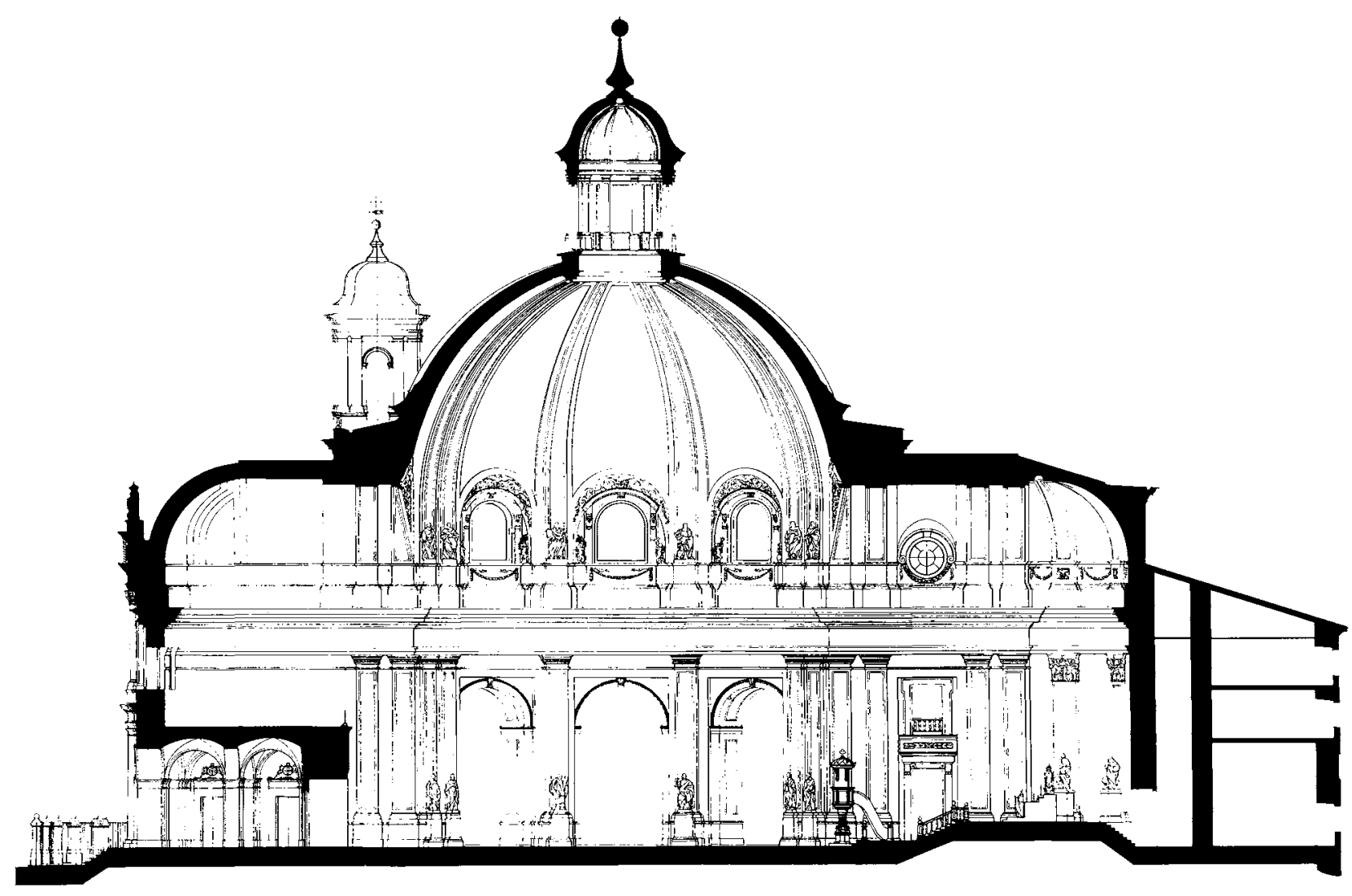

Sección longitudinal.

que, en 1768, se paralizan las obras por defectuosas, y se retira Fray Antonio.

Después de múltiples vicisitudes e intervenciones -incluso del Consejo del Rey Carlos III-, el agrimensor Antonio Plo cierra la cúpula y los franciscanos le encargan a Sabatini la terminación de la fachada y del convento, finalizándose las obras de construcción en 1784 .

Por tanto, hasta esta fecha de terminación han pasado 23 años. Dos siglos antes, el monasterio de El Escorial se habia hecho en 21 años, con un programa mucho más complejo y extenso, e incluso acabado interiormente. Hacemos esta comparación para resaltar lo caótico de la gestión y construcción de San Francisco el Grande, frente a la obra que popularmente se toma como ejemplo de obra lenta.

Consideramos que, a partir del 1784, comienzan los cambios de uso, así como reformas y restauraciones que se inician con la conversión del convento en cuartel, durante la invasión francesa.

José Bonaparte destina el convento-cuartel a hospital y encarga a Silvestre Pérez el proyecto para transfor- mar la basílica en Salón de Sesiones de las Cortes, lo que no se lleva a efecto.

Con la desamortización de Mendizábal de 1835, y la Ley de exclaustración de 1837, la iglesia se cierra al culto.

Por dos veces las Cortes deciden destinarla a Panteón de Hombres llustres, lo que no se llega a realizar.

Hasta 1860 hay varias renovaciones del plomo de cubierta, en parte por haber sido sustraido cuando era cuartel. En este año se restaura y se inaugura el templo, pero continúa la reparación de bóvedas y cubiertas.

Esa situación permanece hasta que, en 1878, Cánovas del Castillo decide la total restauración y ornamentación, por lo que se vuelve a cerrar la iglesia.

Se hace un nuevo emplomado de cubierta. Se colocan las estatuas exteriores realizadas en Inglaterra, mientras que interiormente se ejecuta toda su ornamentación, pinturas, esculturas, estucos, mármoles, dorados, etcétera.

Se abre provisionalmente la iglesia para los funerales de Alfonso XII, y en 1889 al culto, aunque no está terminada. 


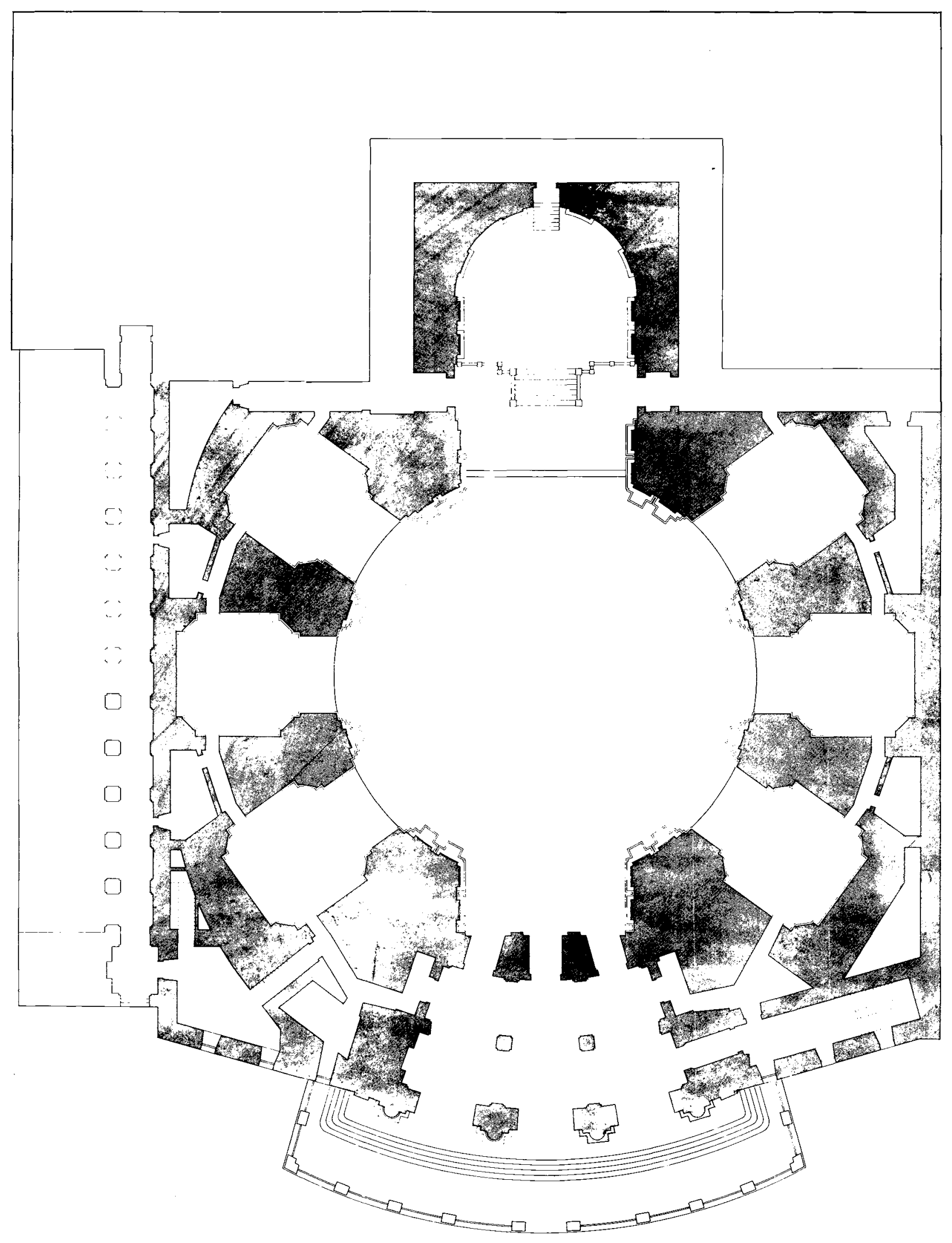




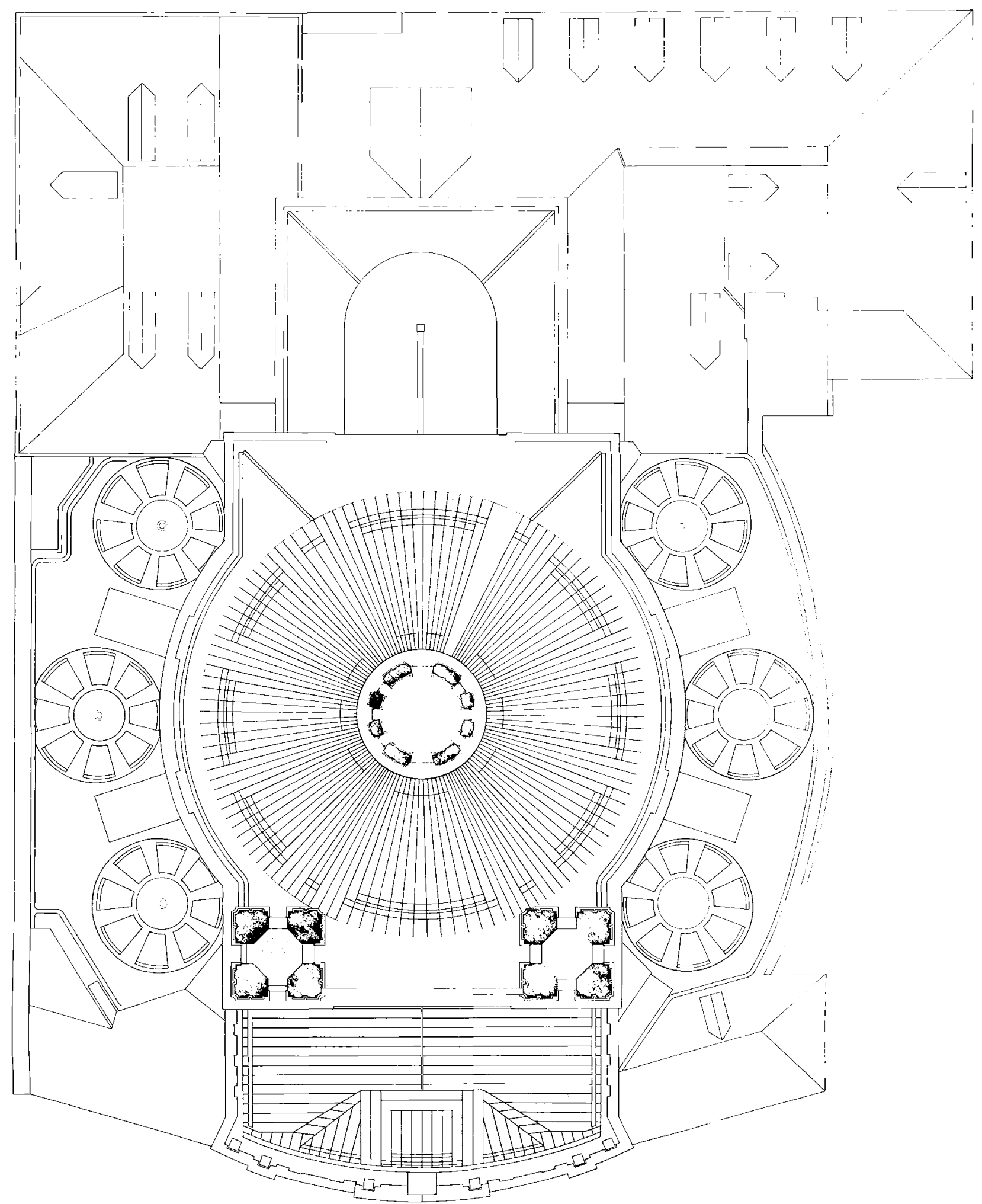


En los años posteriores se suceden nuevamente reparaciones y levantamientos en el plomo de cubierta; hasta el punto de que, apenas se han terminado, ya tienen que comenzarse otra vez.

La situación de la tecnologia es tan deficiente que incluso los andamios hay que importarlos de Francia o de Italia.

Paralelamente, las pinturas se han ido deteriorando y comienza también su restauración, realizada muchas veces por sus propios autores.

La Junta del Tesoro Artístico protege la iglesia durante la guerra civil y se destina a almacén de obras de arte.

Al final de la guerra la iglesia vuelve a ser cuartel.

En el año 1940 se acomete una restauración de urgencia.

Años más tarde hay un proyecto de restauración total, de la Dirección General de Arquitectura, que no se lleva a cabo.
Durante los años sesenta se procede al derribo del cuartel para construir la Avenida de los Reyes Católicos.

En 1973, el Patrimonio del Estado realiza la última res. tauración como hemos indicado al principio.

El 10 de octubre de 1980, por Real Decreto, se declara Monumento Histórico-Artístico Nacional, ejerciendo desde entonces su tutela y defensa el Ministerio de Cultura.

Como se desprende claramente del estudio histórico, el templo tiene un problema de filtraciones constantes que acaban por destruir las pinturas. A lo largo de estos 200 años se suceden reparaciones en el plomo (4 veces en su totalidad y 19 parcialmente), incluso hasta la más reciente, sin que se logre poner fin al problema. Las filtraciones se podian producir por tres puntos: cubierta, muros o huecos, y capilaridad de arranque de muros.

Como el mayor deterioro se estaba produciendo en las pinturas de las cúpulas, habia que centrarse en ese

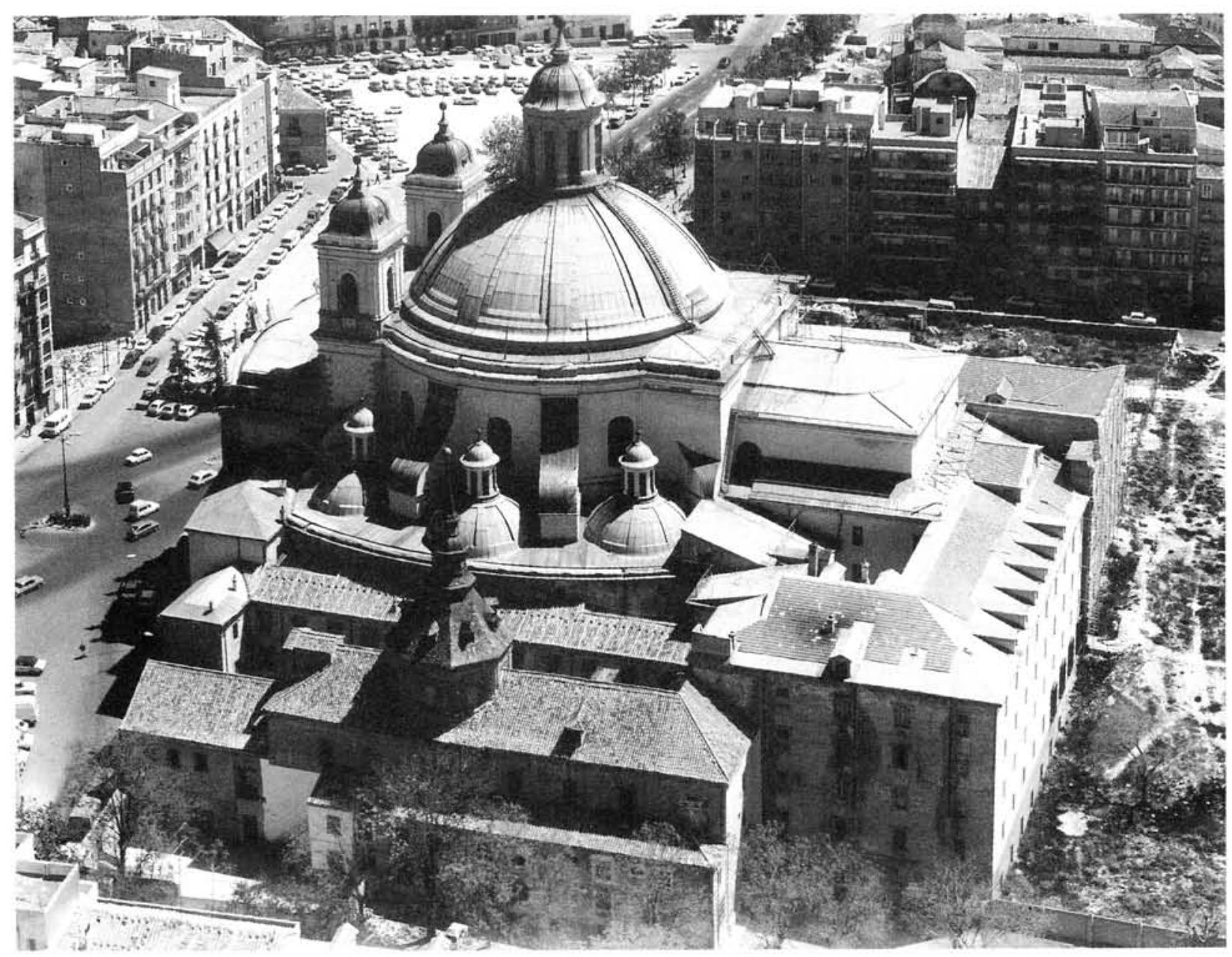

Vista aérea durante la restauración. 


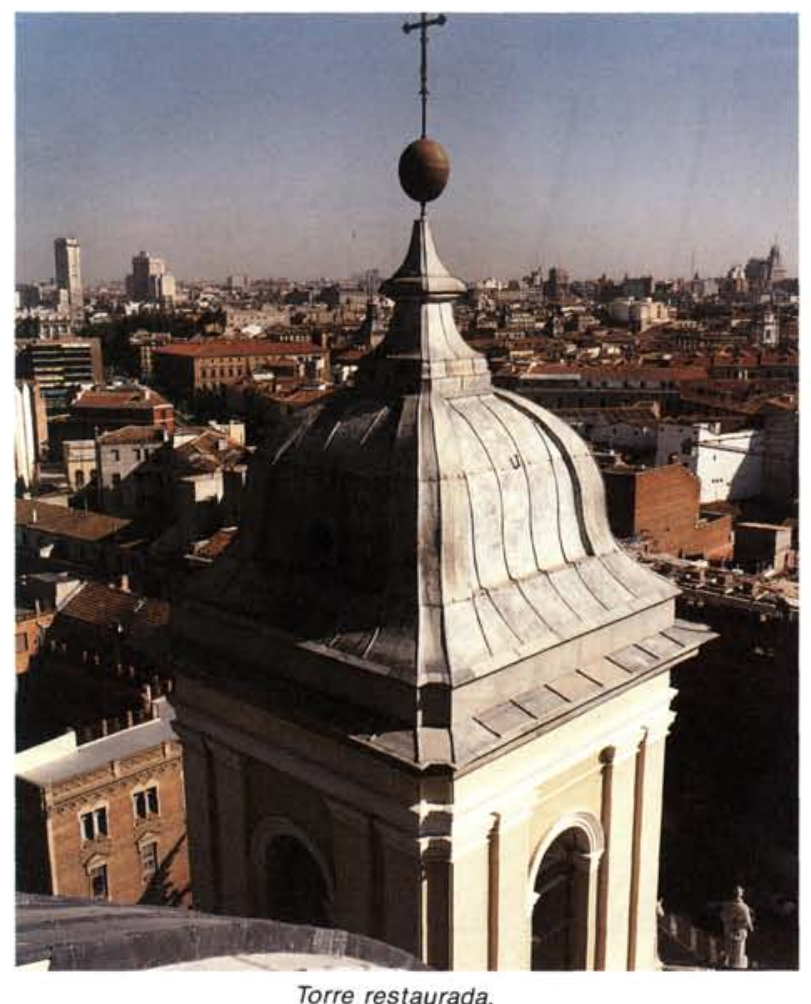

punto principalmente; pues consideramos que la iglesia contiene una muestra única del conjunto de pintores de todo el siglo XIX, empezando por Goya y Bayeu, y pasando por Dominguez, Ferrán, Casado del Alisal, Martinez Cubells, Plasencia, Pidal, Muñoz Degrain, Moreno Carbonero, Maella, Carlos Luis Ribera, etc., además de los restauradores como Garnelo, Contreras, Salaberria, etc. Por tanto era un condicionante, por encima de cualquier otra consideración, el impedir absolutamente la entrada de agua que ya habia deteriorado, de forma irrecuperable, gran parte de algunas pinturas.

Por otro lado, parecia que los muros no eran los causantes del problema, sino que el agua entraba por las cúpulas y llegaba al interior absorbida por la gran cantidad de yeso que tenían. Por último, para ver las filtraciones que podian producirse por capilaridad del arranque de muros, se hizo un estudio del saneamiento comprobando que, aparte de estar el edificio situado en una hondonada por donde pasaba un arroyo (como ya fue observado por Juan Bautista Sachetti, cuando era Arquitecto del Ayuntamiento y tuvo que aprobar la colocación del edificio), la evacuación se hacía directamente al terreno posterior, que la absorbia, lo que no era una solución definitiva.

Con el conjunto de los datos conseguidos por nosotros, más las visitas realizadas con especialistas, hicimos un análisis y valoración de todo; y teniendo presente que el presupuesto que nos fijaba la Dirección General de Bellas Artes era capaz para una parte sola-

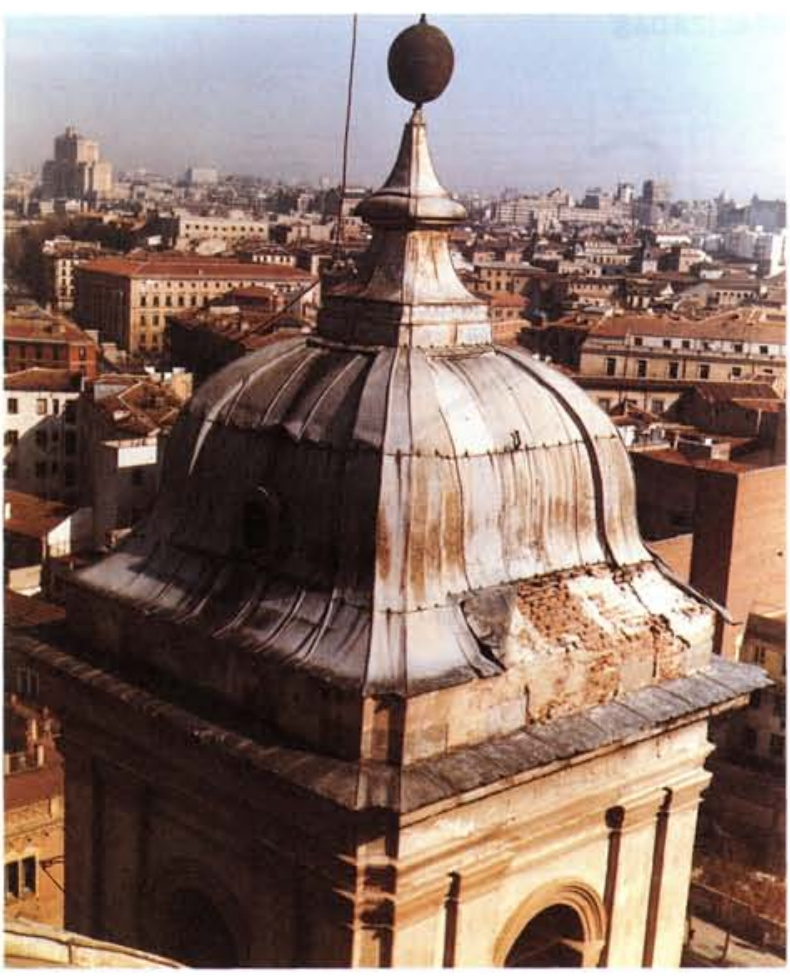

Torre antes de la restauración.

mente, elaboramos un informe previo. En él planteábamos un Esquema Director contemplando la totalidad de la obra dividida en once programas o etapas, para que el Ministerio pudiese realizar las fases que le conviniera.

Nos parece importante la necesidad de realizar un Esquema Director como base de desarrollo del proyecto o de los varios a que pueda dar lugar. Es un documento que se justifica plenamente en diferentes aspectos:

- Constituye un análisis, de todo punto necesario, para la comprensión global de actuaciones; si bien teniendo presente que las distintas fases de obra han de establecerse atendiendo, no sólo a lo que cons. tituye cada una en si misma, sino también a las im. plicaciones entre todas ellas.

- Sirve como guia general para la redacción de futuros proyectos.

- Facilita la previsión de inversiones al definir y valorar programas de actuación.

- Es de máxima utilidad como orientación para determinar prioridades y proyectos especificos.

- Se trata de un proceso abierto, sujeto a crítica y variaciones en función de futuras necesidades, am. pliaciones, etcétera.

http://informesdelaconstruccion.revistas.csic.es 


\section{SOLUCIONES CONSTRUCTIVAS}

\section{REALIZADAS}

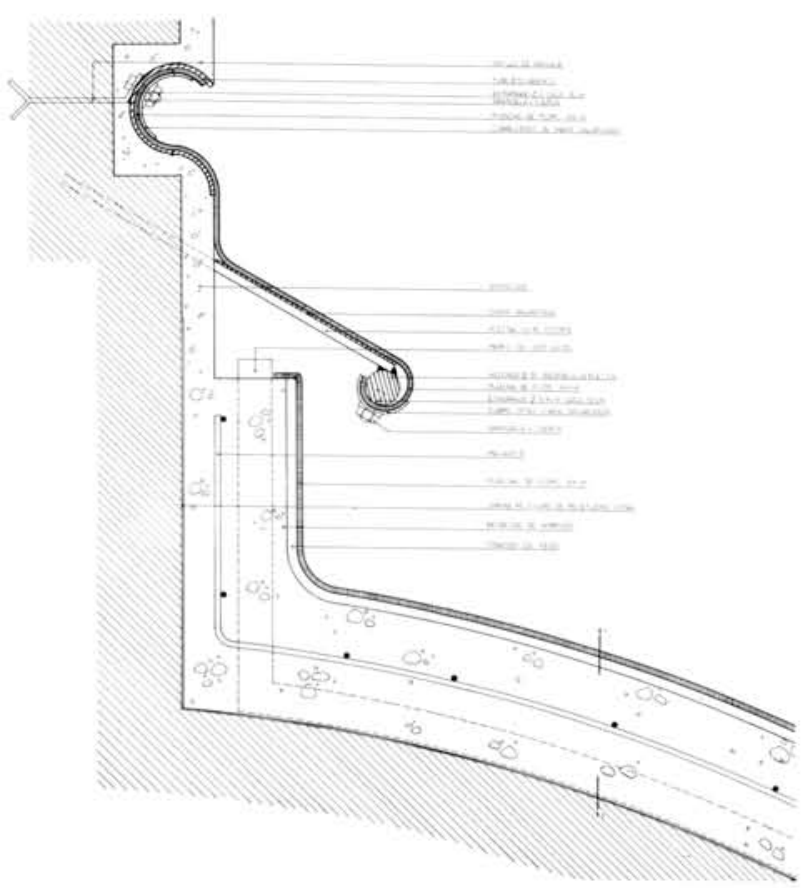

Remate superior del plomo en la cúpula.

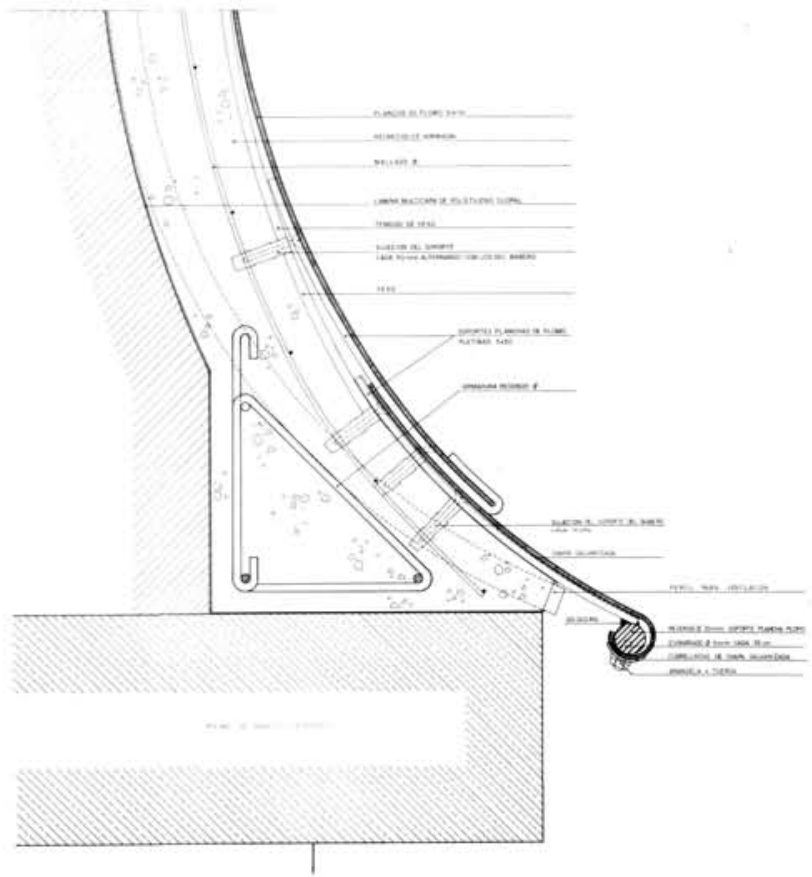

Sujeción de plomo en cúpula.

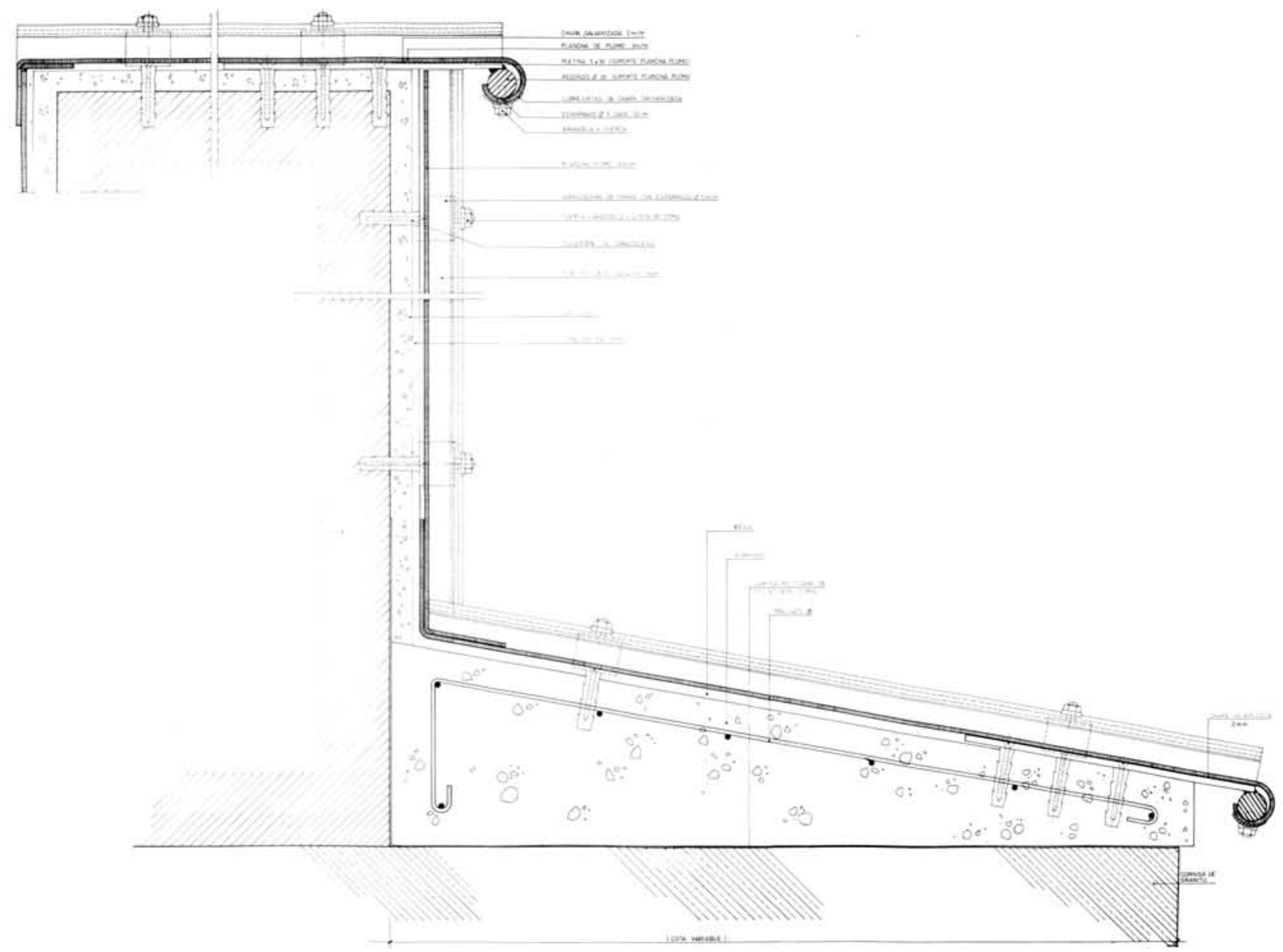


La falta de un Esquema Director ha motivado que, las diversas actuaciones a lo largo de la historia del edificio, hayan sido solamente puntuales, inconexas y, generalmente, desencadenantes de otros problemas.

El presupuesto inicialmente aprobado cubría solamente la reparación de la cúpula central, linterna, presbiterio, coro y sus muros, que constituian las dos primeras fases de nuestro informe.

Vemos que es un templo de planta central, con una cúpula sin tambor; que había tenido cuatro torres, de las que dos habían sido eliminadas y las otras dos están encastradas en la cúpula. Esta es una de las de mayor diámetro que existia en el momento $(33 \mathrm{~m}$ frente a 42 de San Pedro, 43 del Panteón, 31 San Pablo en Londres, 26 Los Inválidos de París, 20 San Marcos de Venecia, 31 Santa Sofía de Constantinopla), y parece que hubo una gran inseguridad en la forma en que se estaba construyendo, puesto que aparte de las discusiones de la Academia sobre su viabilidad, aparentemente se recurrió a una especie de armadura auxiliar formada por unas pletinas, en el sentido de los meridianos, separadas entre sí unos $90 \mathrm{~cm}$ en su arranque y atadas horizontalmente por otras, para poder colocar un tablero de ladrillo apoyado en éllas; y, sobre él, como cimbra, se construyó la bóveda formada por dos roscas de ladrillo y un relleno de cascote suelto. La cimbra está revestida de yeso y sobre éste se realizan las pinturas (al óleo y lienzos pegados en vez de fresco, pues hacía tiempo se habia perdido esta costumbre y su técnica). La acción del agua, junto con el yeso, han deshecho las pletinas de hierro, desprendiéndose las capas en contacto con él $y$, por tanto, las pinturas.

Los muros del falso tambor están realizados con ladriIlo macizo, fabricado a pie de obra, tomados con un mortero de cal y yeso; éste, con la humedad, ha llegado a reventar los enfoscados. Los muros se rematan con una cornisa, cuyas molduras suelen ser de granito las superiores y de corrido las inferiores, si bien he. mos encontrado pintura primitiva imitando granito al picar alguna cornisa, semejante a la que existe en sitios residuales. Los aterrajados están hechos en masa en muchos casos; es decir, no hay ladrillo aplantiIlado debajo, ni volado haciendo la forma, y por tanto todo el espesor de la moldura (en el que se incluye el yeso), no se soporta. Otras veces los vuelos están realizados con ladrillo hueco, lo que nos indica que pertenecen a una restauración relativamente reciente.

Todos los muros, vuelos y salientes se cubren con una plancha de plomo sujeta de diversas formas, pero sin bordón de remate en casi todos los casos, con los baberos mal resueltos y sin goterones. El plomo se coloca en las cubiertas con un engatillado que se suelta.

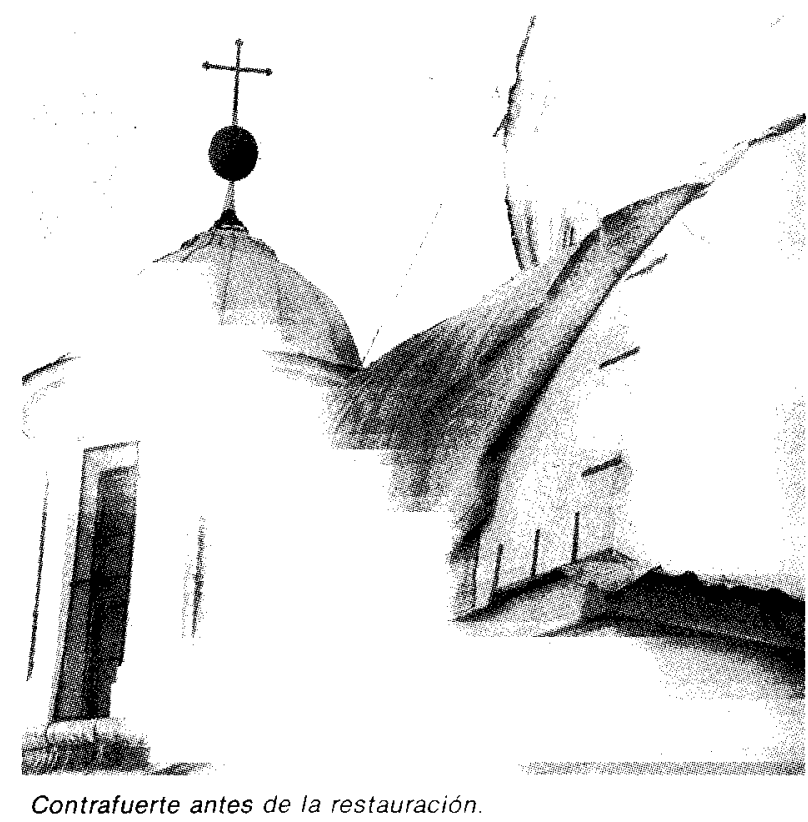

Contrafuerte antes de la restauración
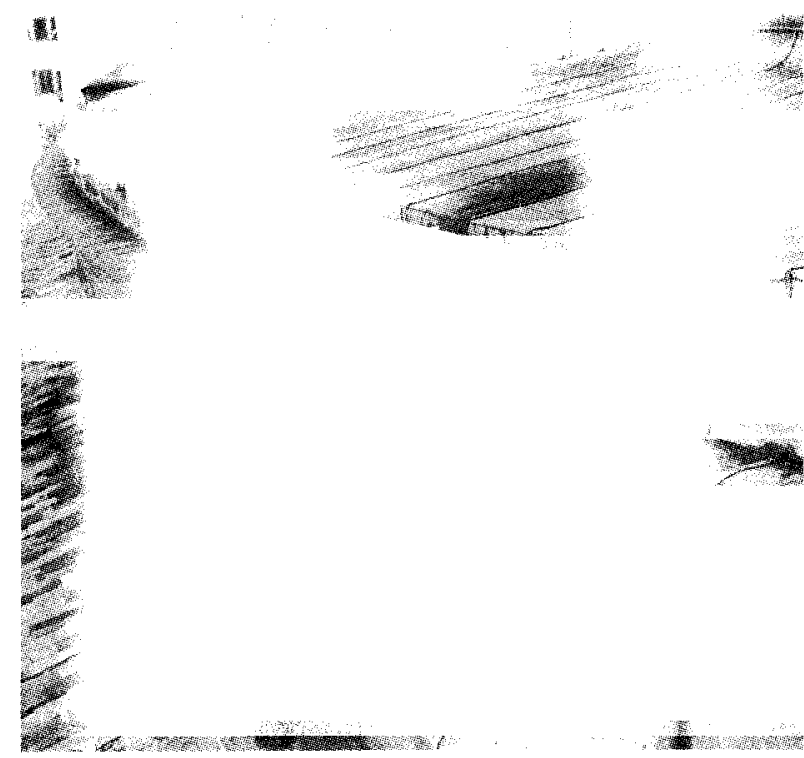

Estado de muros, baberos y canalones
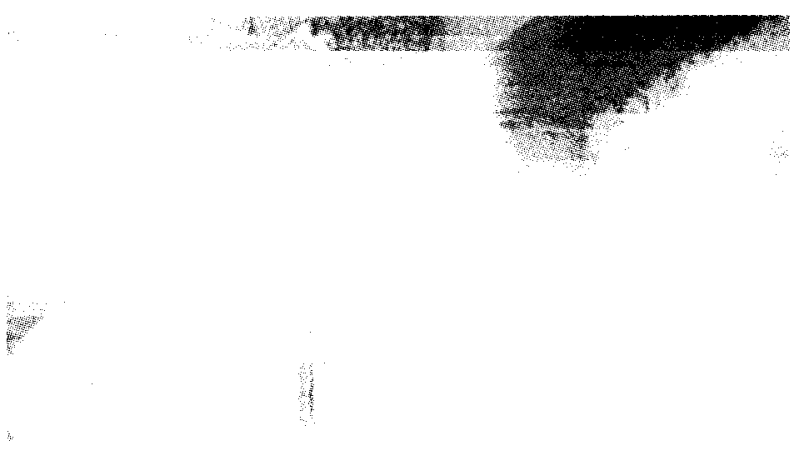

Moldura antes de la restauración.

http://informesdelaconstruccion.revistas.csic.es 

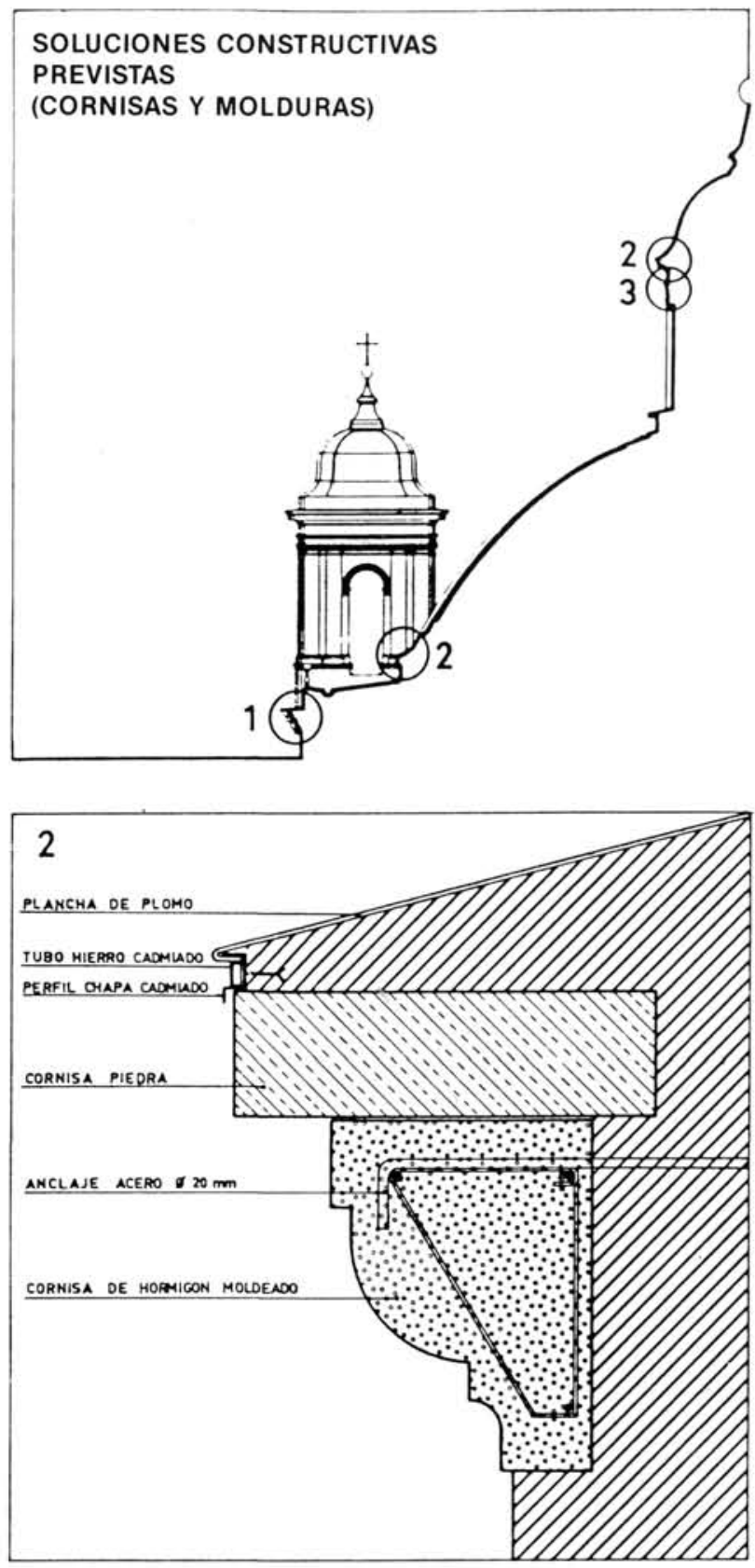

A lo largo de todas las restauraciones se ha insistido en las mismas soluciones constructivas, que la experiencia ha demostrado que son malas:

- Se persiste en colocar el plomo con el mismo engatillado y continúa abriéndose.

- Se han seguido haciendo los aterrajados, que con el yeso de las fábricas se han reventado.

- Se vuelve a hacer la cama de yeso sobre un relleno de cascotes.

- En las últimas se da forma a las molduras hasta con ladrillo hueco y se enfosca con mortero de cemen. to sobre yeso.
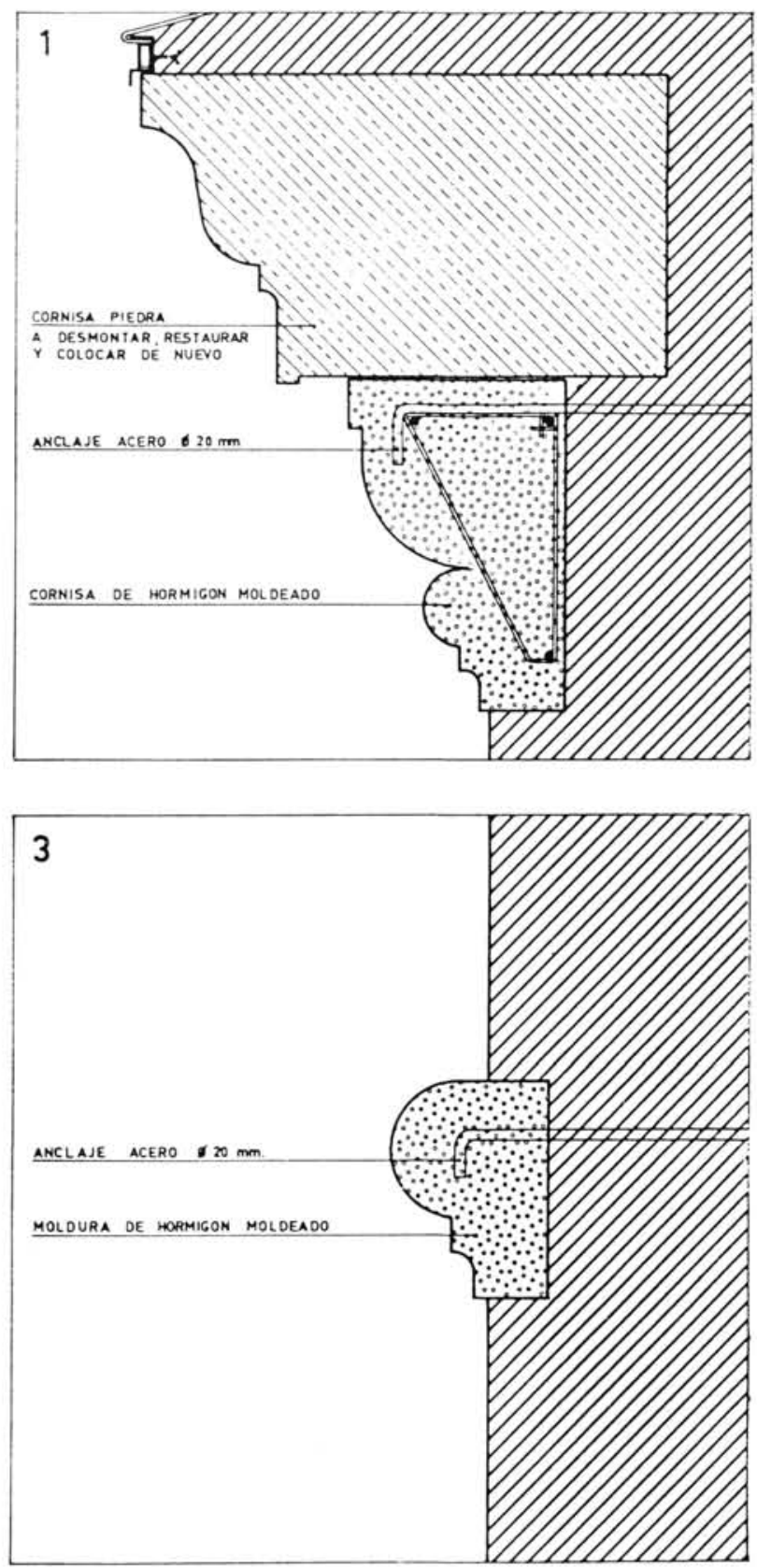

- No se resuelven los problemas de defecto de proyecto (encuentros, limas, canalones, bajantes...).

La basilica tiene, por tanto, unos problemas de diseño arquitectónico y estructural importantes (como son las torres encastradas en la cúpula, ejecución de la cúpula de coro con doble apoyo, etc.), que se resolvieron mal en principio y que se ha continuado insistiendo en ellos.

Comparándolo con los edificios contemporáneos singulares, vemos que la mayoria están construidos en piedra granítica, utilizando la caliza de grano más apretado solamente donde bate el agua o se requiere un aspecto de resistencia (aportación de los arquitectos italianos que vinieron con Juvara para la construcción del 
Palacio Real), o un trabajo fino de molduración. Sin embargo, en nuestro caso la cornisa de remate es de granito y bajo ella las molduras son de mortero (actualmente de cemento). Desconocemos las razones para decidir esta solución y suponemos que son de tipo eco. nómico al ver la austeridad decorativa del edificio (ven. tanas del tambor sin molduras, sin jambas, ni imposta de arranque del arco, ni peana, ni elemento alguno que las relacione con la fachada). Son caso especial las del presbiterio que, aparte de lo antes dicho, tienen una forma geométrica indeterminada y una descompuesta colocación en el paño.

Los contrafuertes, que tienen una importancia primordial tanto en planta como en el aspecto exterior de la iglesia, tampoco adquieren ni una forma ni un adorno que los enriquezca; hasta el punto de quedar cortados simplemente los extremos que se unen al presbiterio o con una extraña solución de encuentro con las cubiertas de ambos lados de la fachada y embutiéndose en las torres.

También la imposta de arranque del falso tambor, que recorre horizontalmente todo el edificio, es una senciIla piedra de granito o, en muchos casos, de mortero, sin ningún tipo de molduración.

El revoco de las fachadas tiene un dibujo de sillares, que al llegar a las esquinas de las torres no puede jugar con las auténticas piedras por tener unas dimensiones irregulares.

Después de este primer análisis arquitectónico y constructivo, pasamos a describir el proceso seguido.

Primeramente se hizo una recogida de muestras de muros, plomo, etc., y se desmontó un trozo de cubierta de la cúpula para ver su estado, comprobando que, bajo el plomo, la cama de yeso llegaba a tener hasta $10 \mathrm{~cm}$ de espesor para regularizar el relleno de cascotes de ladrillo, cal, cemento y yeso completamente descompuesto. Esta capa hacía de "esponja" y depósito del agua que se filtraba y transmitia poco a poco al inte. rior.

De los análisis del plomo se obtuvo que contenia cantidades apreciables de arsénico y plata como era usual en épocas anteriores (cuando lo recomendable es una pureza al 99\%), sustancias que le habian hecho quebradizo y se supone que lleno de fisuras y poros por donde se filtraba el agua. Además, había planchas apoyadas directamente sobre mortero de cemento que tenían verdaderos agujeros por la descomposición del plomo.

Por tanto, se nos planteaba que el material de acabado de cubierta no cumplia la misión de impermeabili-

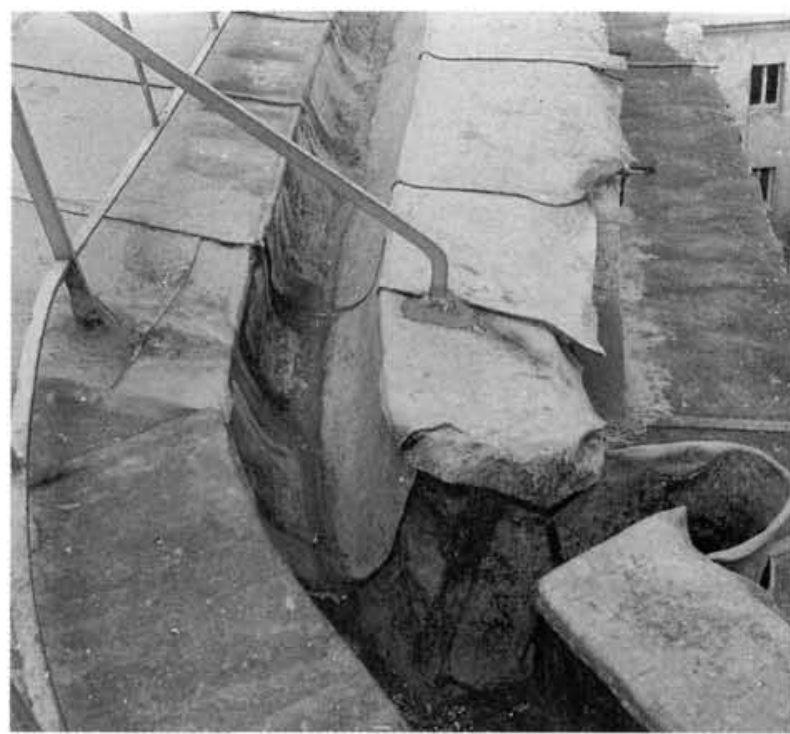

Lima y buzón.

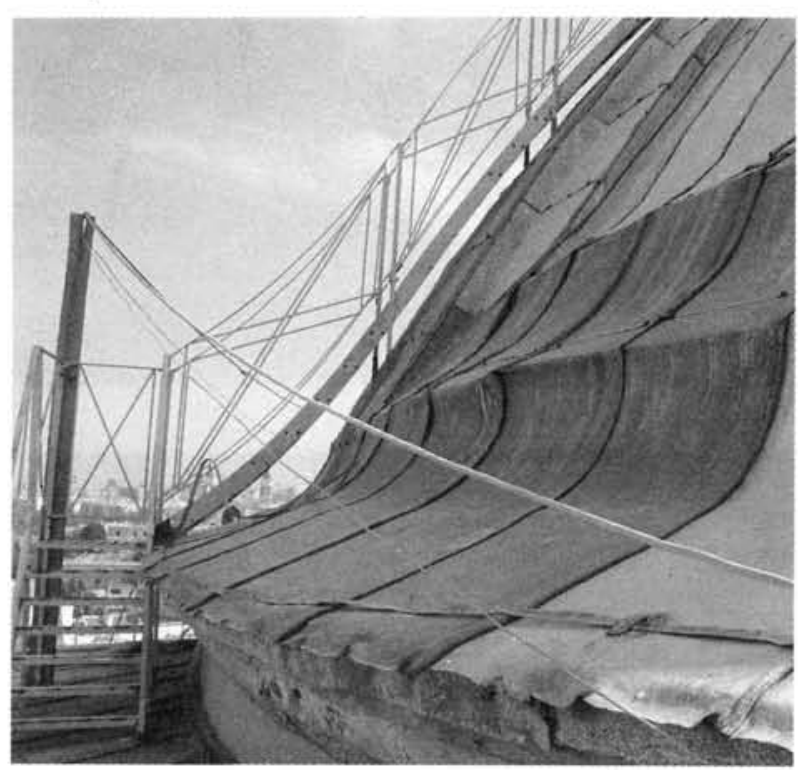

Estado del plomo de cúpula.

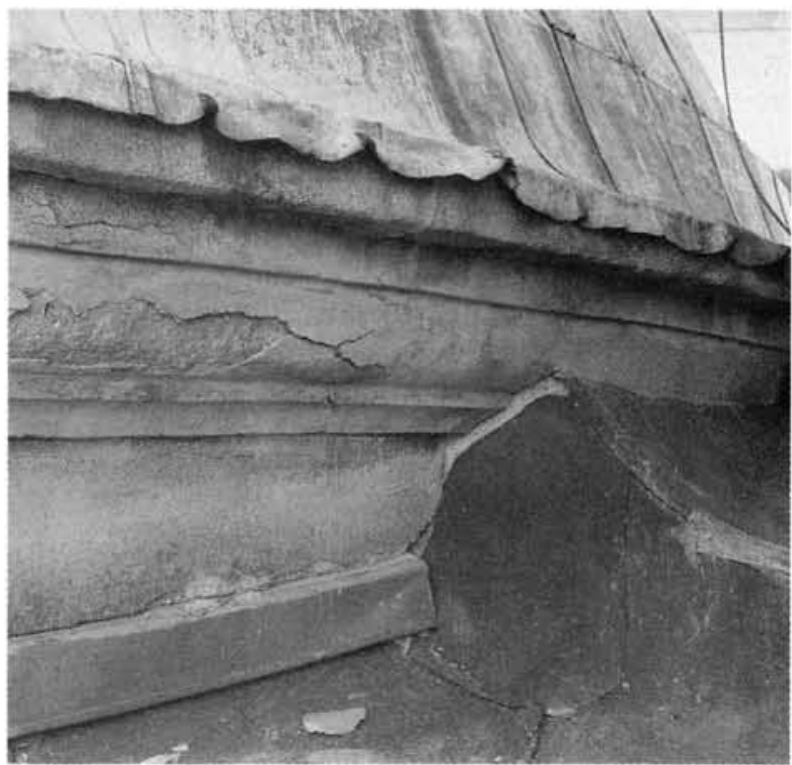

Molduras y remate de plomo de cúpula.

http://informesdelaconstruccion.revistas.csic.es 


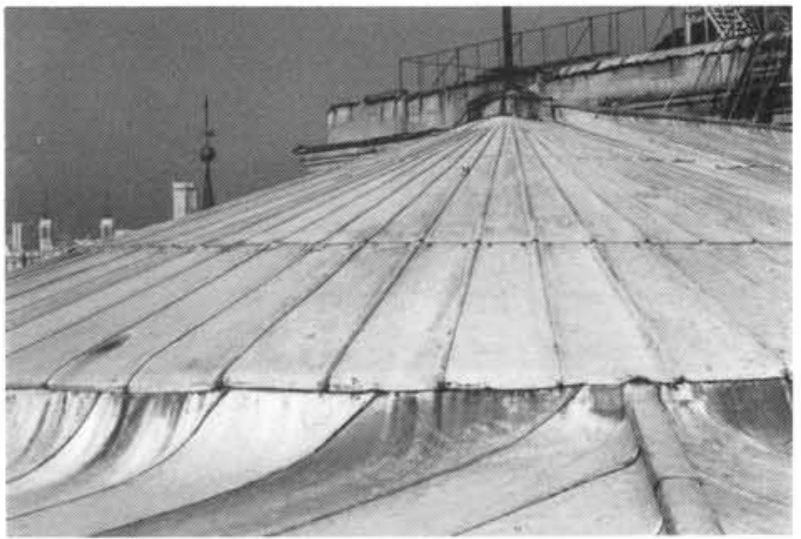

Presbiterio antes de la restauración.

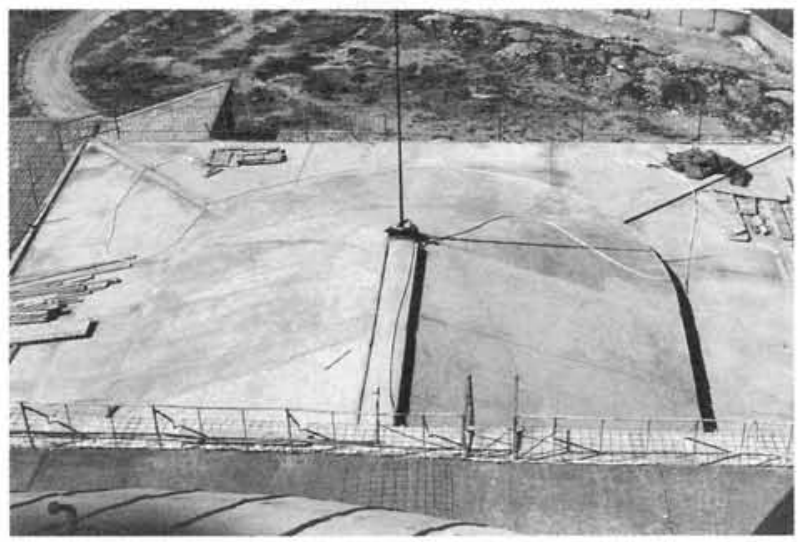

Presbiterio en ejecución.

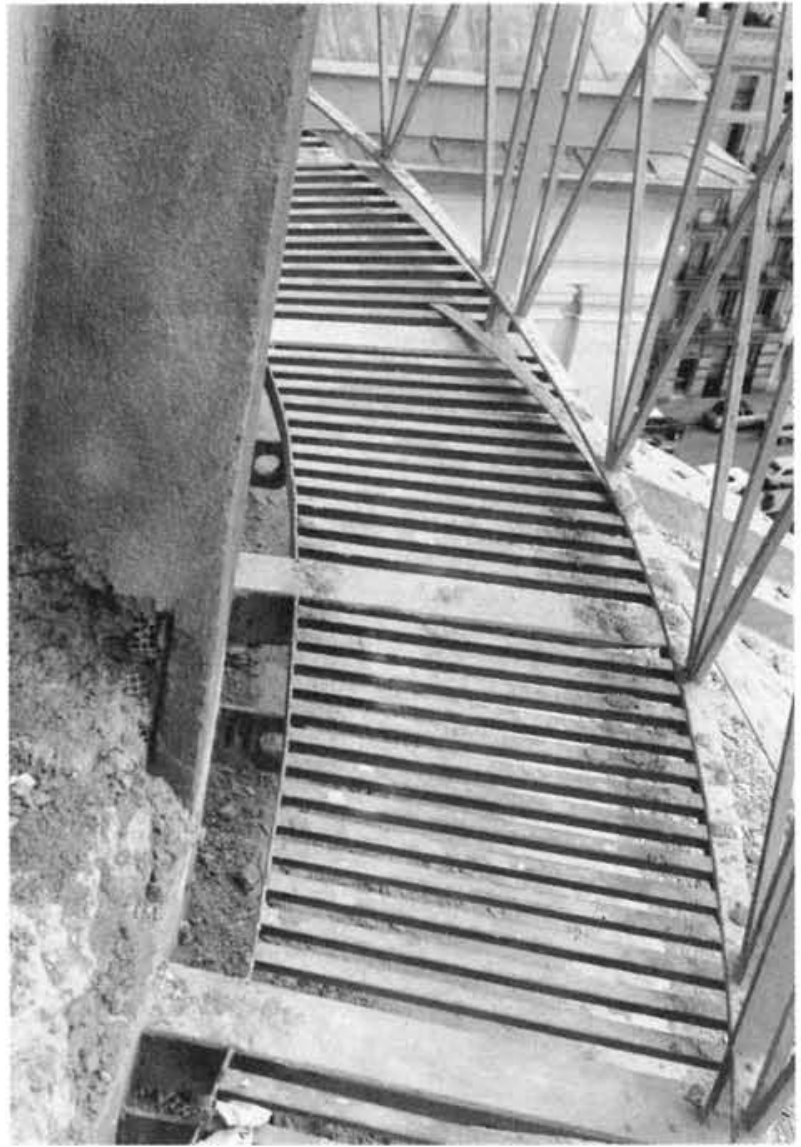

Detalle pasarela de la linterna en ejecución.

(c) Consejo Superior de Investigaciones Científicas Licencia Creative Commons 3.0 España (by-nc)

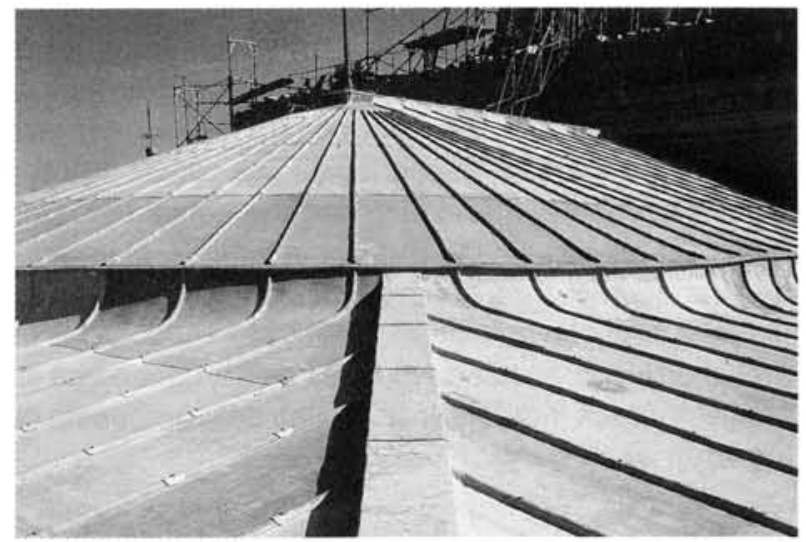

Presbiterio acabado.

zación que se le confiaba y su función iba a ser solamente mantener el aspecto externo para no variar la fisonomia del edificio. Debiamos confiar el aislamiento a un material que regularizara la superficie rugosa, una vez limpia de cascotes, y se adaptara a una forma de casquete esférico con nervaduras. También teniamos que evitar que el cemento normal estuviese en contacto con el yeso de los morteros de las fábricas, para evitar otra vez las reacciones químicas.

Se nos aconsejó la solución que se habia usado en la Clerecia de Salamanca, pero optamos por la espuma de poliuretano que nos daba el espesor necesario en cada caso y se podia corregir el vertido en cada momento. Entonces la solución completa de la cubierta consistió en recibir una armadura a la fábrica de ladriIlo - mediante unos taladros y mortero epoxi-, verter la espuma regularizando la superficie y dejando asomar la armadura para atar un mallazo y gunitar hormigón que no estaria asi en contacto con los yesos que habia en la fábrica. Todo ello se hizo de forma que se conservara el perfil primitivo de la cubierta. Como nos preocupaba la "respiración" del interior de la cúpula, se dejaron metidos unos semitubos en el sentido de los meridianos, bajo el aislamiento, para que ventilara.

Con la forma ya definitiva, se extendió la cama de yeso para apoyar el plomo.

En el proyecto habiamos previsto que, al desmontar el plomo, se perderia gran cantidad de planchas por lo quebradizo que estaba, especialmente en los engatiIlados. Estudiado este tema, vimos que ya era preocupación en otros paises, y más concretamente en Francia, donde Viollet-Le Duc habia escrito sobre la calidad del plomo, tipos de engatillados y despiece que, posteriormente, se pusieron en práctica en la restauración de la catedral de Reims, bombardeada en la guerra del 14. Sin embargo, el engatillado tradicional que se usaba en otras latitudes con cambios de temperatura y hu. medad poco bruscos, aqui habia fracasado.

http://informesdelaconstruccion.revistas.csic.es 
Se recomendaba entonces la solución de armar el nervio con un baquetón, pero sabiamos y habíamos com. probado que la madera con la humedad también afectaba al plomo y los mismos cambios bruscos de temperatura, humedad y sequedad, caracteristicos de $\mathrm{Ma}$ drid, terminaban deformándola. Buscamos un material inerte al plomo, humedad y temperatura, y nos inclinamos por un derivado del polivinilo que era suficientemente elástico para adaptarse a las formas de la cubierta y con dureza como para acoplar el plomo. La manera de sujetarlo era mediante tacos expansivos sobre la placa de hormigón y acoplar la plancha de plomo, solapando una sobre otra y atornillada al taco con un cubrejuntas. De esta forma aprovechábamos mayor número de planchas de plomo al no tener que hacer el engatillado tradicional y se conseguia que, en caso de sustitución de una pieza, resultara un trabajo sencillo. A pesar de esto, la cantidad de plomo recuperado en buen estado no era suficiente para toda la cúpula y hemos tenido que recurrir a plomo nuevo, de color diferente, que se ha colocado en los nervios y borde de la cúpula, como en algún tiempo estuvo de forma parecida en las torres.

En cuanto a las grapas o ganchos, sabiamos que entre el plomo y el hierro se forma un par eléctrico con la humedad; además, al estar el hierro clavado sobre yeso, se habian destruido gran parte de los ganchos antiguos, cosa que no ocurre utilizando cinc o cobre, por lo que decidimos hacerlos de pletina de este último.

Ha sido una preocupación constante el proporcionar, en todos los casos, un remate con bordón que hiciese de goterón en todos los aleros de plomo, que a su vez nos daría un acabado de una línea recta exteriormente. Además era necesario hacer también un goterón en las cornisas o impostas donde fuera preciso, y resolver de una forma definitiva los baberos en su unión con los paramentos verticales.

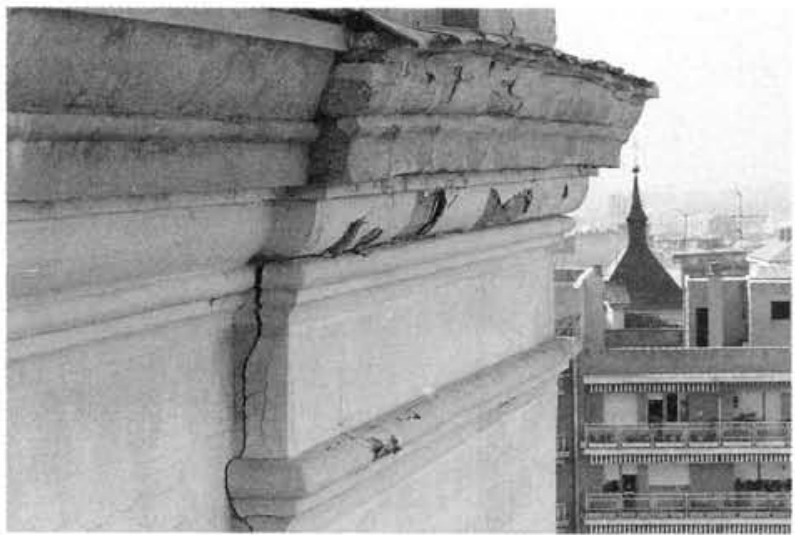

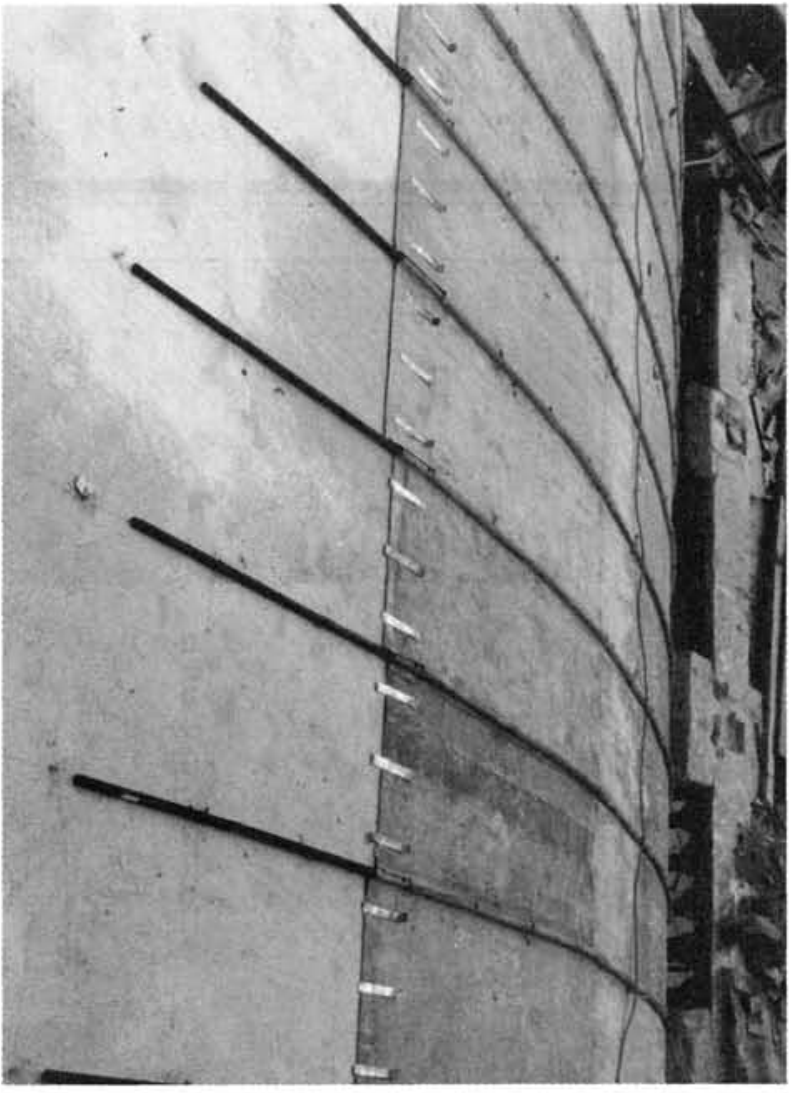

Grapas de cobre en los faldones.

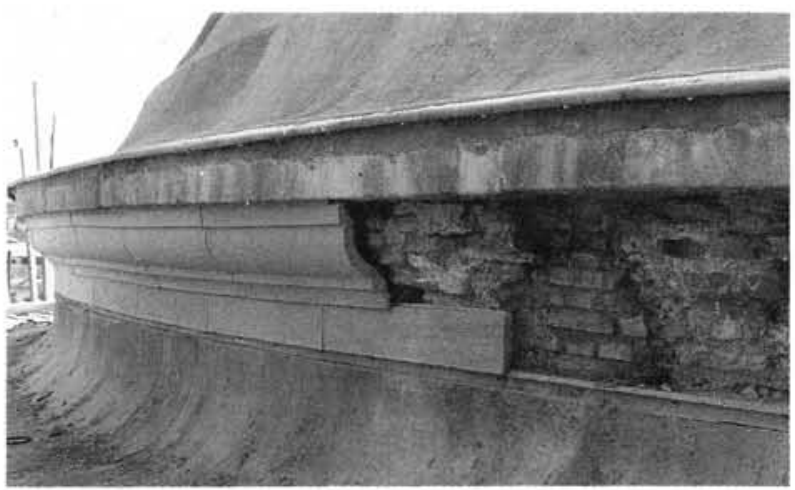

Piezas prefabricadas al pie de la cúpula y remate del plomo.

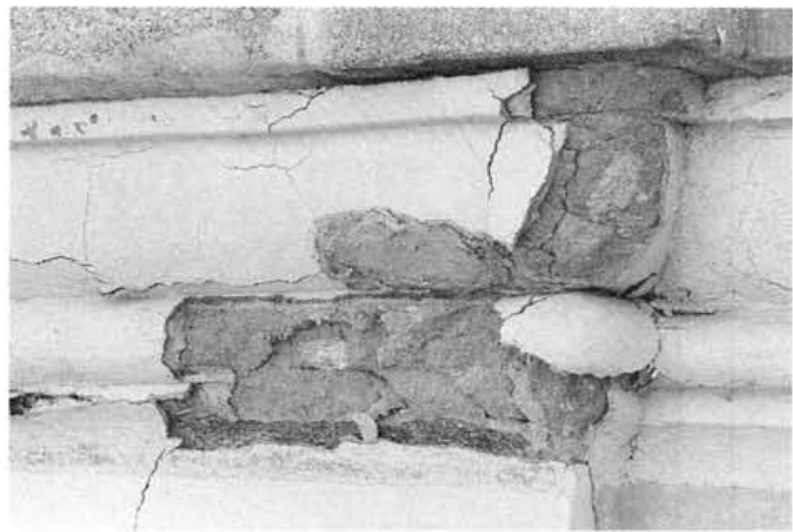



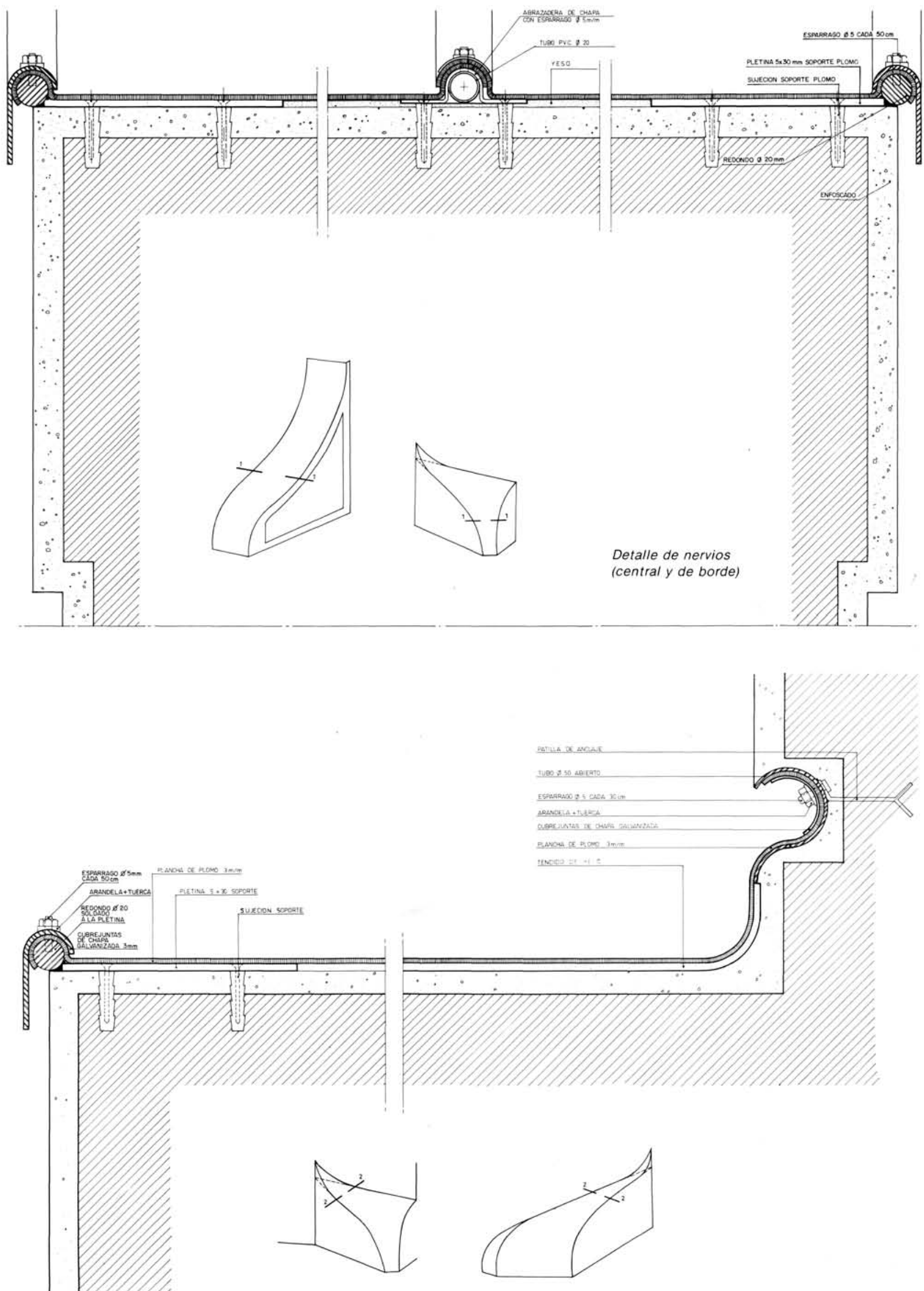


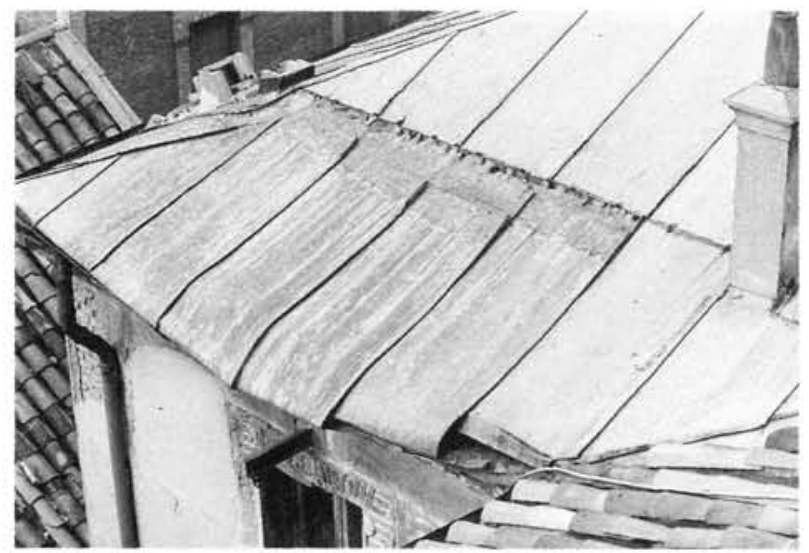

Plomo desprendido.

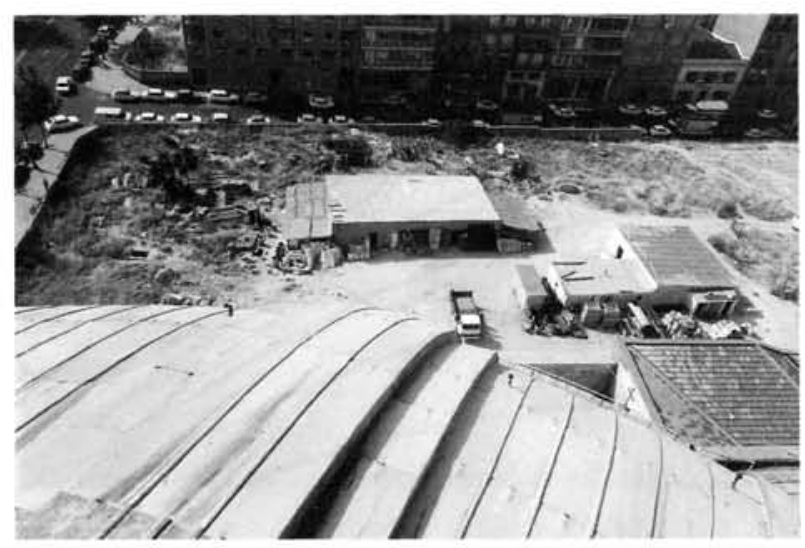

Cúpula en ejecución.

En el primer caso, el bordón se ha resuelto con una pieza formada por una chapa soldada a un tubo redondo (para adaptarlo a las curvas fácilmente), todo ello pintado con una imprimación que no ataque al plomo. Estas piezas se han recibido a todos los bordes y se revisten con el plomo de cubierta que se adapta al tubo y se sujeta con un tornillo. De igual manera se ha hecho con las aristas de los nervios y de los contrafuer. tes.

Como segundo aspecto a tener en cuenta, para proteger las fachadas, era el repaso y nueva ejecución de goterones. A lo largo de las restauraciones se habian sustituido y fabricado piedras o molduras en las que se habia despreciado el goterón, aunque si lo tuvieran las piezas antiguas. Se han repasado todas las piezas que lo tenian, o haciéndolo de nuevo en las que no.

Por último, el tercer aspecto a tener en cuenta es el de los baberos, su sujeción al muro y solape. En general, todos eran de chapa de cinc embutida en el muro y con un nervio de borde (aunque alguno habia hasta de aluminio gofrado); pero la conocida dilatación del cinc, en tanta longitud, los habia deformado y habia hecho saltar el revoco que estaba en contacto con él. Proyecta-

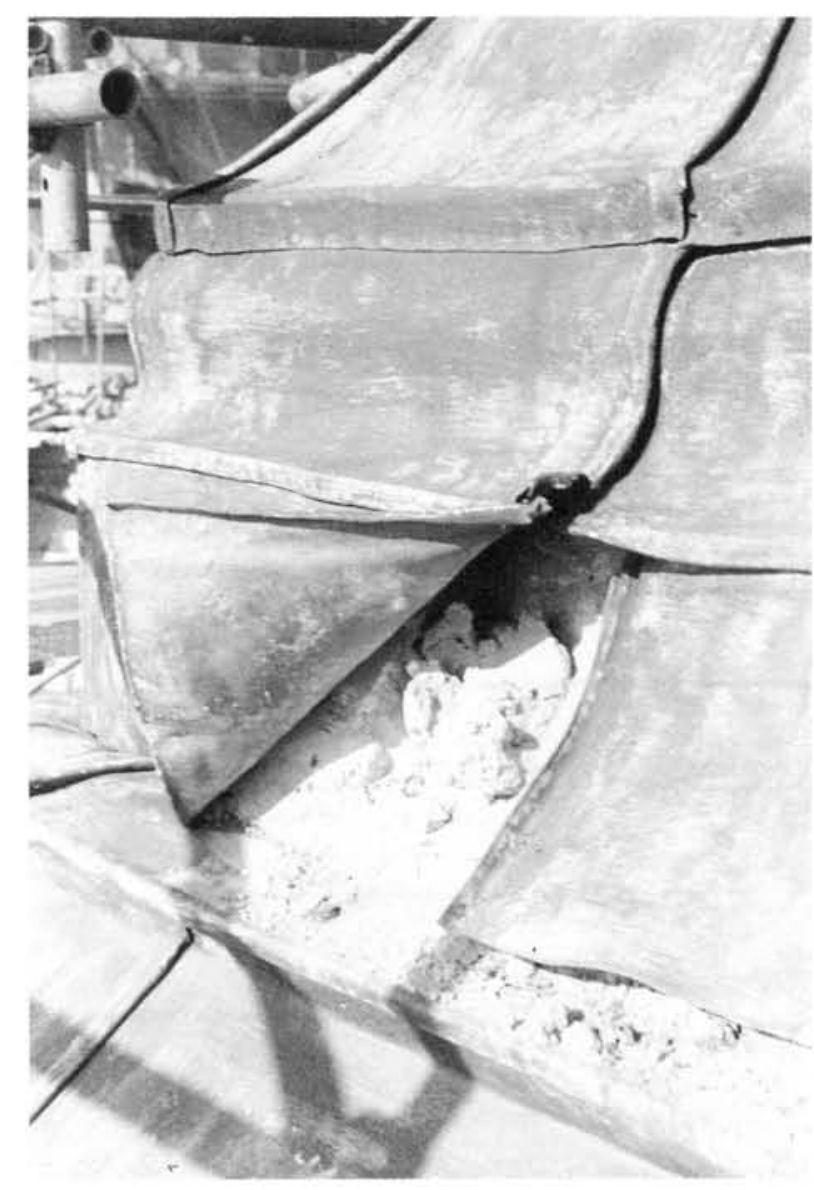

Torre II. Estado de la cama de yeso.

mos una pieza empotrada en el muro, constituida por un tubo redondo, abierto, con sección en C, donde entraba el plomo y se sujetaba en su interior. La arista superior de la $C$ hacia de goterón y en fachada se vería una línea oscura de sombra que daba un dibujo limpio.

Sin embargo, las dificultades constructivas de la pieza proyectada, especialmente en la curvatura, nos hizo reconsiderar la solución y hacerlo definitivamente en chapa plegada, semejante a una pieza ya normalizada y de uso común en paises centroeuropeos, con una sección más constructiva para sujetar el plomo, una solución de goterón más definida y mayor facilidad para acoplar a las diferentes soluciones de baberos.

Respecto a las cornisas, molduras, pilastras, basa y capiteles, estaban hechos todos de mortero en masa, que en las recientes restauraciones sólo eran de cemento, con algún relleno de ladrillo hueco para aligerar, sin que apareciera ningún vestigio de ladrillo aplantillado o los vuelos característicos, y variando el dibujo primitivo de la moldura. Los morteros, de cemento convencional, se habian tirado sobre paramentos con ladrillos en mal estado, aglomerado con cal y yeso.

http://informesdelaconstruccion.revistas.csic.es 


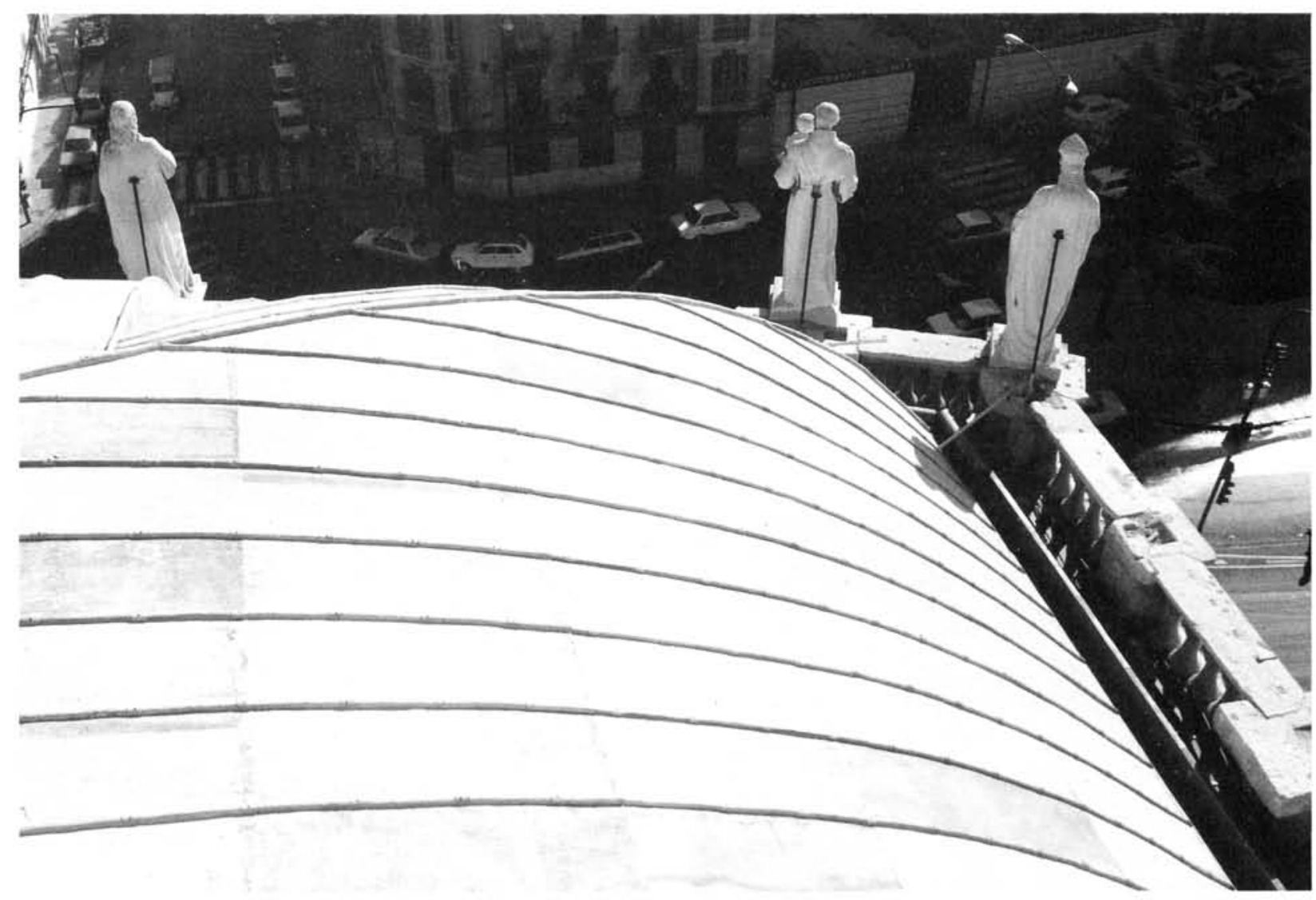

Nueva cubierta del coro.

Ante la descomposición de la base (que al limpiarla se desmoronaba e hizo desprenderse alguna piedra de la cornisa de granito), habia que reconstruir las molduras de forma que no tocaran el ladrillo, sujetarlas por puntos y que su aspecto externo fuera como de piedra caliza o granítica que se intentaba imitar con el revoco, en su dia, y la pintura recientemente.

Recurrimos a un hormigón de cemento blanco y árido de caliza o granito, cuya sujeción no fuera por adherencia a la fábrica y dejándolo separado de ésta para que ventilara. El aspecto de acabado era el de la pie. dra que se pretendía en su día, reconstruyendo las molduras primitivas, y con la seguridad de no ser necesario su mantenimiento ni nuevo revoco.

Sobre los paramentos se procedió al picado, limpieza, tendido de cemento resistente a los yesos, un enfoscado armado y el revoco definitivo.

Las soluciones que hemos descrito las hemos puesto en práctica tanto en el presbiterio, como en la cúpula y el coro; es decir, en una cubierta de paños planos con poca inclinación, un casquete esférico con diferentes niveles y una cubierta con doble curvatura y también diferentes niveles, resultando en todos los casos buenos detalles constructivos.
Donde hemos producido una reforma más importante ha sido en el coro. Entre la gran cantidad de restauraciones y cambios de plomo que ha tenido la iglesia, el coro ha sido la parte que más veces se ha tocado por ser sus filtraciones constantes, hasta el punto de hacer desaparecer casi las pinturas, pues las goteras eran reales físicamente. (Como anécdota podemos contar que el organista tocaba con paraguas y un casco fabricado por él mismo, para protegerse del agua y los trozos de yeso que caían).

En principio nos parecia extraña la forma de la cubierta del coro, con un canalón sobre un peto que se apoyaba en la balaustrada, que casi la ocultaba, y una solución de buzón y bajante pintoresca (que se ha seguido restaurando de igual forma a lo largo del tiempo).

Levantada la cubierta de plomo en la zona próxima a las torres, se vio que la cama de yeso estaba sobre un tablero apoyado en un relleno de cascotes (incluso de ladrillo hueco). Se siguió profundizando hasta otra segunda capa semejante y por fin se llegó a la verdadera bóveda de ladrillo macizo. En los hombros de la bóveda estaba el remate del muro del coro con un lecho donde habia descansado el primitivo canalón; y entre éste y la balaustrada había un enlosado de granito que recorria toda la cornisa haciendo una balconada alrede- 
dor del coro. La bóveda, como ya hemos dicho, es de ladrillo macizo, con una estructura aparente de dos arcos que arrancan del muro de fachada y van a apoyar en el muro entre las torres, sobre el arco toral del coro. Al hacer la limpieza y descubrimiento de toda la bóveda, aparecieron dos tirantes de hierro forjado, uno en el muro entre las torres y otro formando una poligonal, haciendo anillo en todo el perímetro de los muros de fachada, a la altura del enlosado, como para impedir que el empuje los abriera.

Parece que en su momento no supieron dar salida a las aguas que recogía el pasillo y se levantó la cubierta primeramente hasta el nivel del peto de la balaustrada, de forma que el agua saltara por encima de ella. Como no dio resultado, volvieron a levantar la cubierta, se hizo el peto sobre la balaustrada, el canalón, el buzón y la bajante, y se siguió restaurando con esta for. ma, pero sin resolver las humedades.

Tomamos la decisión de devolver el perfil primitivo y dejar la balaustrada libre, transparente, como un balcón corrido, que además del efecto ligero de remate de muro que pretendia (como está en el Palacio Real), servia de recorrido de reconocimiento y limpieza de esa cubierta. Hemos buscado un diseño de canalón que im- pida el salto del agua y desde el exterior, a través de los balaustres, proporcione una imagen uniforme.

La realización de esta fase de obra es fruto de la estre. cha colaboración entre todas las personas que estamos interviniendo en élla, constituyendo un conjuntado equipo. Las experiencias de adopción de algunas soluciones sobre la marcha, con las aportaciones personales de cada especialista, han permitido recuperar algunos oficios casi perdidos, como el de plomero, asi como la formación de aprendices que ya están en disposición de ser oficiales. Antonio Escribano del Castillo y Francisco Javier Gómez Martínez, aparejadores; Guillermo Garcia Moneo, maestro plomero; Francisco Oviaño, maestro portlandista; y Wenceslao García, maestro pintor, forman parte del equipo que está llevando a cabo la obra.

El Ministerio de Cultura tiene previsto continuar la acción hasta completar la total restauración del conjunto, siguiendo el plan trazado en el Esquema Director. Es decir, tras esta fase se seguirá con la restauración de las cúpulas de las capillas, de la fachada principal, de las laterales de la iglesia y de la integridad del convento, asi como una revisión y adecuación del saneamiento general.

\section{publicación del IETcc / CISC}

\section{ACUEDUCTOS ROMANOS EN ESPAÑA Carlos Fernández Casado}

Prof. Dr. Ing. de Caminos, Canales y Puertos

Esta publicación se compone de una serie de articulos, publicados en la Revista "Informes de la Construcción", en los cuales se hace un análisis de los acueductos romanos que existen en España y el balance de las condiciones de conservación en que se encuentra cada uno de ellos, incluyendo referencias históricas y literarias. Se ha ilustrado con la reproducción de la valiosa documentación gráfica que posee el prestigioso autor.

Un volumen encuadernado en couché, a dos colores, de $21 \times 27$ centimetros, compuesto de 238 páginas, numerosos grabados, dibujos, fotos en blanco y negro y figuras de linea.

Precio: España, 1.500 ptas., 21 \$ USA.

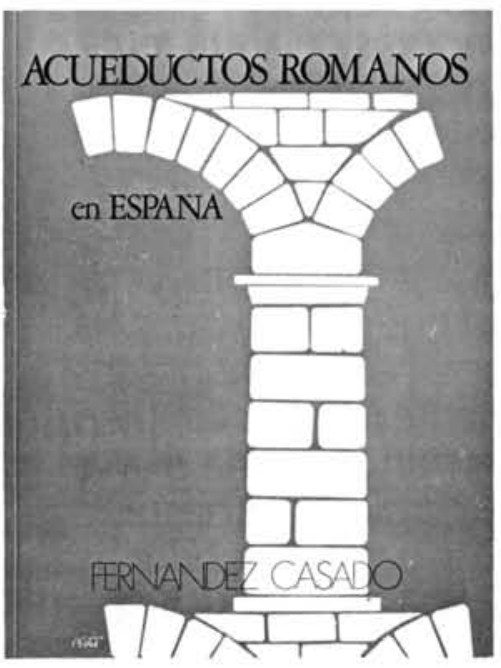

